\title{
Novitates
}

PUBLISHED BY THE AMERICAN MUSEUM OF NATURAL HISTORY CENTRAL PARK WEST AT 79TH STREET, NEW YORK, NY 10024 Number 3488, 34 pp., 13 figures, 2 tables

October 27, 2005

\section{Restudy of Anshunsaurus huangguoshuensis (Reptilia: Thalattosauria) from the Middle Triassic of Guizhou, China}

\author{
JUN LIU1 AND OLIVIER RIEPPEL ${ }^{2}$
}

\begin{abstract}
We here describe the complete skeletal anatomy of Anshunsaurus huangguoshuensis that previously remained unknown. The description includes a review of the dorsal side of the skull as well as the first description of the ventral side of the skull and of the postcranial skeleton. A new phylogenetic analysis supports the monophyly of Askeptosauridea and Thalattosauridea; Endennasaurus is found to be closely related to Askeptosauridae.
\end{abstract}

\section{INTRODUCTION}

Thalattosaurs are a monophyletic clade of Triassic marine reptiles with modest specialization toward an aquatic life (Nicholls, 1999). The phylogenetic position of thalattosaurs within amniotes is controversial: They have been suggested to be diapsids with possible affinities to the Lepidosauromorpha (Romer, 1956; Rieppel, 1998), Archosauromorpha (Evans, 1988), to be Neodiapsida inc. sed. (Benton, 1985), or else to be the sister taxon of Sauria (Müller, 2004) or of Ichthyopterygia (Müller, 2003).

Thalattosaurs are first known from the Upper Triassic of California, North America, represented by Thalattosaurus and Nectosaurus (Merriam, 1904, 1905, 1908). Thalattosaurus is also known from the Middle Triassic of British Columbia. Two additional, but very incompletely known taxa, Agkistrognathus and Paralonectes, as well as an as yet undetermined form have been reported

\footnotetext{
${ }^{1}$ Division of Paleontology, American Museum of Natural History; Lamont-Doherty Earth Observatory, Columbia University, Palisade, New York, NY 10964 (liujun@amnh.org).

${ }^{2}$ Department of Geology, The Field Museum, 1400 S. Lake Shore Drive, Chicago, IL 60605-2496 (rieppel@ fieldmuseum.org).
} 
from the same deposits in British Columbia (Nicholls and Brinkman, 1993). To the present day, Askeptosaurus from the Grenzbitumenzone (Anisian/Ladinian) of Monte San Giorgio, Switzerland/Italy (Nopsca, 1925; Kuhn-Schnyder, 1952), remains the best known thalattosaur (Müller, 2002, in press). In addition, the Grenzbitumenzone of Monte San Giorgio yielded the two monotypic genera Clarazia and Hescheleria (Peyer, 1936a, 1936b). Blezingeria from the Ladinian of Germany may be a thalattosaur (Rieppel, 1998), but a definite assignment has to await additional material (Müller, 2002). Endennasaurus from the Norian of Italy was identified as a thalattosaur when first described (Renesto, 1992), an assessment that was confirmed by Müller et al. (2005). Many wellpreserved thalattosaur specimens have been discovered in Guizhou, China; Anshunsaurus and Xinpusaurus are erected based on these specimens (Liu, 1999; Rieppel et al., 2000; Yin et al., 2000; Liu and Rieppel, 2001). Moreover, there are several fragmentary records of thalattosaurs from the Ladinian of Spain (Rieppel and Hagdorn, 1998), the Carnian of the Julian Alps (Dalla Vecchia, 1993), the Norian of Austria (Müller, 2002), the Anisian and Carnian of Nevada (Sander et al., 1994), and the Norian of British Columbia (Storrs, 1991).

The lack of consensus on the phylogenetic relationships among thalattosaurs is not only due to character incongruence, but also a result of fragmentary preservation of fossils or incomplete anatomical knowledge of the wellpreserved specimens. For example, only the dorsal view of the skull of Anshunsaurus has previously been described (Liu, 1999; Rieppel et al., 2000). Here we describe the complete skeletal anatomy of Anshunsaurus and discuss its relationship with other thalattosaurs.

The Triassic marine reptile Anshunsaurus huangguoshuensis was originally described by Liu (1999) as a sauropterygian on the basis of dorsal view of a skull. The specimen was recognized as thalattosaurian by Rieppel et al. (2000). Only later were the ventral side of the skull and the postcranial skeleton of the holotype prepared, as well as an additional specimen made available for study.

Institutional AbBREViations: GMPKU, Geological Museum of Peking University;
Beijing. Gmr, GGSr, collections at the Geological Survey of Guizhou, Guiyang. IVPP: Institute of Vertebrate Paleontology and $\mathrm{Pa}$ leoanthropology, Chinese Academy of Sciences; Beijing. PIMUZ, Paläontologisches Institut und Museum der Universität Zürich. SPC, Center of Stratigraphy and Paleontology, Yichang. UCMP, University of California Museum of Paleontology, Berkeley.

MATERIAL: IVPP V11835 (holotype), a skeleton lacking most of the hind limbs and most of the caudal vertebrae. The specimen is composed of seven parts, viz., the head (11835-1) (fig. 1), the neck (11835-2) (fig. 4 ), the main body of the trunk and the forelimbs (11835-3) (fig. 5), the posterior part of the trunk (11835-4) (fig. 6), a few caudal vertebrae (11835-5) (fig. 7), and the distal part of a fibula (11835-6). The first three blocks are consecutive; blocks $11835-4$ and 188355 are also consecutive, but some bones are missing between them. The calcite vein that cuts across block 11835-4 separates the left side, which is offset posteriorly relative to the right side. IVPP V11834 (fig. 3) is an articulated, perfectly preserved skeleton, with only the last few caudal vertebrae and a few phalanges missing.

\section{SYSTEMATIC PALEONTOLOGY}

\author{
THALATTOSAURIA MERRIAM, 1904 \\ ASKEPTOSAURIDAE KUHN, 1952
}

ANSHUNSAURUS LIU, 1999

Anshunsaurus huangguoshuensis Liu, 1999

DiAgnosis (revised): An askeptosaurid thalattosaur differing from Askeptosaurus by the maxilla forming part of the anteroventral orbital margin; fusion of the postorbital and postfrontal; the posterolateral process of the frontal extending posteriorly far beyond the anterior margin of lower temporal fossa, narrowly approaching but not contacting the supratemporal; the long and slender ventral process of the squamosal extending to the lower margin of the cheek; jugal with an elongate posterior process; lateral exposure of the angular equal to that of the surangular; deltopectoral crest on the humerus developed; fibula expanded.

LOCALITY AND HoRIzON: Wayao Member, Falang Formation, Ladinian or Carnian (up- 
per Middle or lower Upper Triassic), Xinpu, Guanling County, Anshun area, Guizhou Province, southwestern China.

\section{MORPHOLOGICAL DESCRIPTION}

The two specimens are similar in size, but the holotype IVPP V11835 is a little bit longer than IVPP V11834. The holotype is mainly exposed in dorsal view, whereas the skull, pectoral girdle, and pelvic girdle are also prepared from the ventral side. Specimen IVPP V11834 is mainly preserved in ventral view with most vertebrae in lateral view. All the description of Askeptosaurus refers to Müller (2002, in press) other than specific mention.

\section{SKULL}

The description of the skull is almost exclusively based on the holotype (IVPP V11835) (fig. 1). The skull is slightly dorsoventrally compressed. The anterior part and two sides of the skull in ventral side are covered by the closely attached lower jaw.

\section{Premaxilla}

The paired premaxillae are exposed in dorsal view only. They are slender and rather elongated elements, extending over more than half of the entire skull length as in $A s$ keptosaurus. They compose the main part of the rostrum. The lateral margins of the rostrum gradually assume a straight and parallel course before the snout terminates in a blunt tip. The premaxillae meet in a straight dorsomedial suture. They form tapering posterior processes that contact the anteromedial processes of the frontals, thus separating the nasals from each other.

Although the anterior margin of the external nares is obscured through breakage, it is conceivable that the premaxilla forms the anterior margin of the external naris as in primitive diapsids generally. The left side of the skull shows the premaxillary-maxillary suture to extend from the anteroventral (anterolateral) margin of the external naris in an anterolateral direction. A few straight, longitudinally directed striations are distinct on the dorsal surface of the rostrum.

The left and right premaxillae bear eight to nine teeth respectively. The height of the teeth ranges from $14 \mathrm{~mm}$ to $19 \mathrm{~mm}$ (about $17 \mathrm{~mm}$ ); the width at the base ranges from 6 $\mathrm{mm}$ to $7 \mathrm{~mm}$. The tip of the premaxillae is edentulous. Tooth implantation is subthecodont; the teeth are unicuspid and apically recurved. The enamel surface of each tooth is striated toward the apical area. The third tooth on the right premaxilla is remarkable smaller than all other teeth; it probably represents a newly erupted replacement tooth. In specimen IVPP V111834, the anteriormost premaxillary tooth is smaller than all the succeeding ones.

\section{MAXILLA}

Both maxillae are exposed in dorsal view only. They are slender and elongated elements, relatively small in comparison to the premaxillae. The maxilla extends anteriorly to a level well in front of the external naris before tapering to a point along the lateral (ventral) margin of the rostrum. It forms most of the ventral (lateral) margin of the external naris, and contacts the nasal by way of a short ascending process directly behind the external naris. This contact separates the prefrontal from the posteromedial border of the external naris. Posteroventrally, the maxilla extends into a process that follows the anteroventral (anterolateral) margin of the prefrontal and meets the suborbital process of the jugal in the anteroventral corner of the orbit. In contrast to Askeptosaurus, the posterior end of the maxilla enters the orbital rim.

The maxillary teeth are incompletely exposed in specimen IVPP V11834 (fig. 2). The number of functional teeth is estimated as seven; the exact number cannot be determined due to the obscure premaxillary-maxillary suture. Tooth implantation again is subthecodont. The shape of the maxillary teeth resembles those of the premaxillary, and their size is similar except for few most posterior teeth.

\section{NASAL}

The small nasals are exposed in dorsal view, situated close to the midline of the skull. The nasals are slender and elongated elements, which define the posterior and dor- 


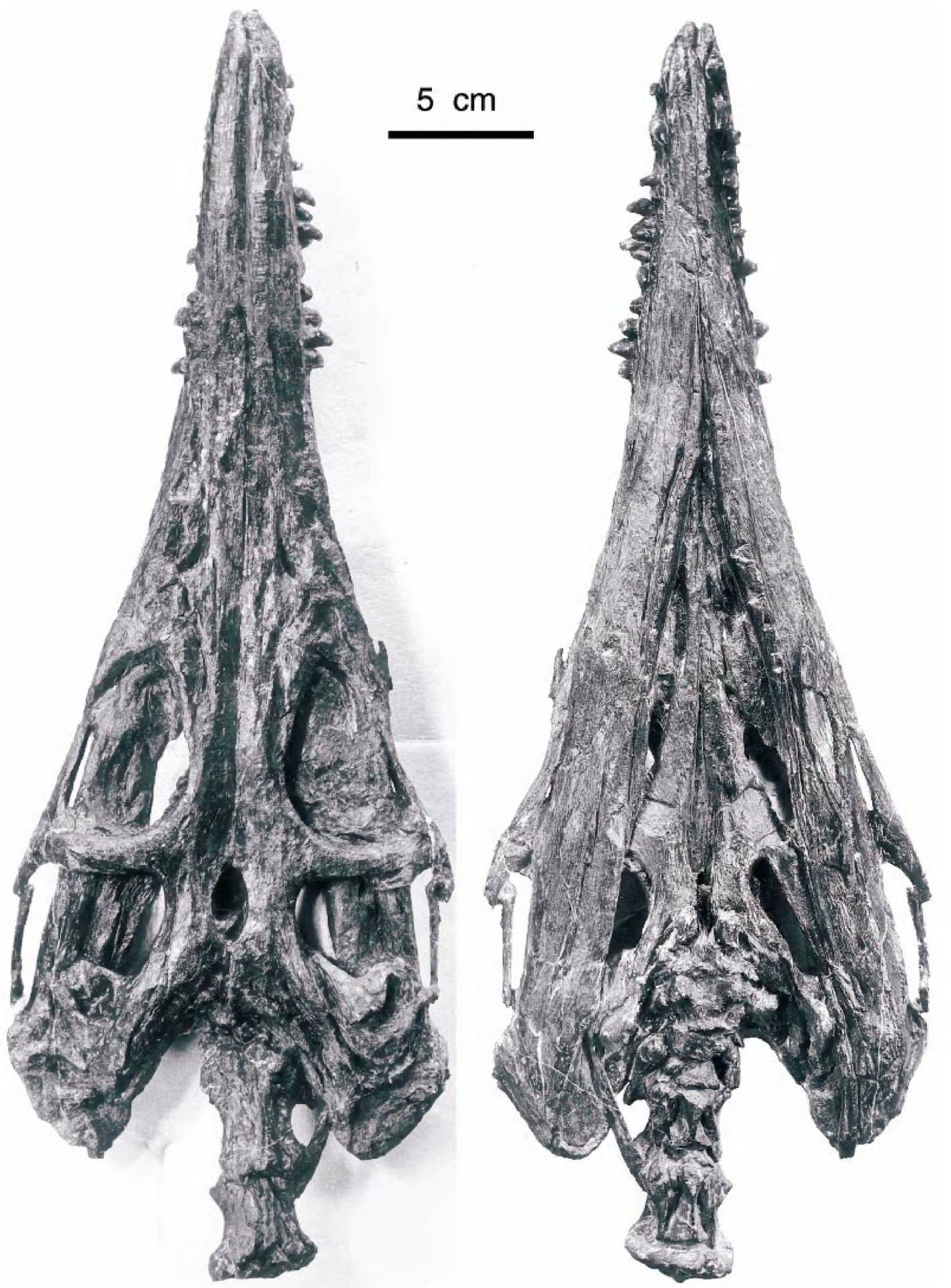

Fig. 1. Anshunsaurus huangguoshuensis, head and first three cervical vertebrae in dorsal and ventral view (holotype, specimen no. IVPP V11835-1). See appendix 1 for anatomical abbreviations. 


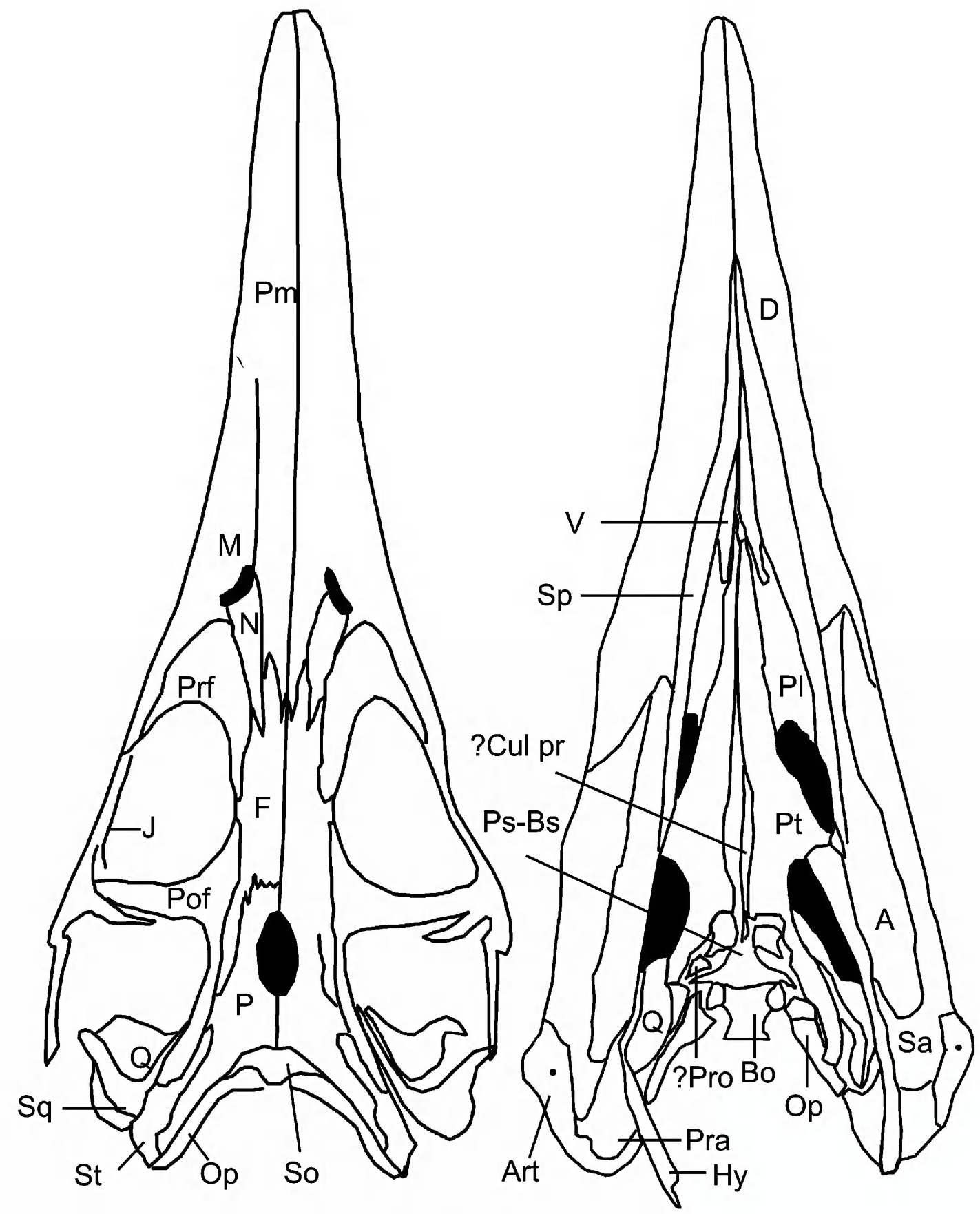

Fig. 1. Continued.

sal (medial) margin of the external nares. Laterally, the nasal meets the ascending process of the maxillae and the anterior end of the prefrontals in a more or less straight, anterolaterally trending suture. Medially, the nasal contacts the premaxillary and the frontal. Anteriorly, the nasals are separated by the premaxillae. The pointed posterior tip of the nasal is embraced by the anterolateral and anteromedial processes of the frontal. The 


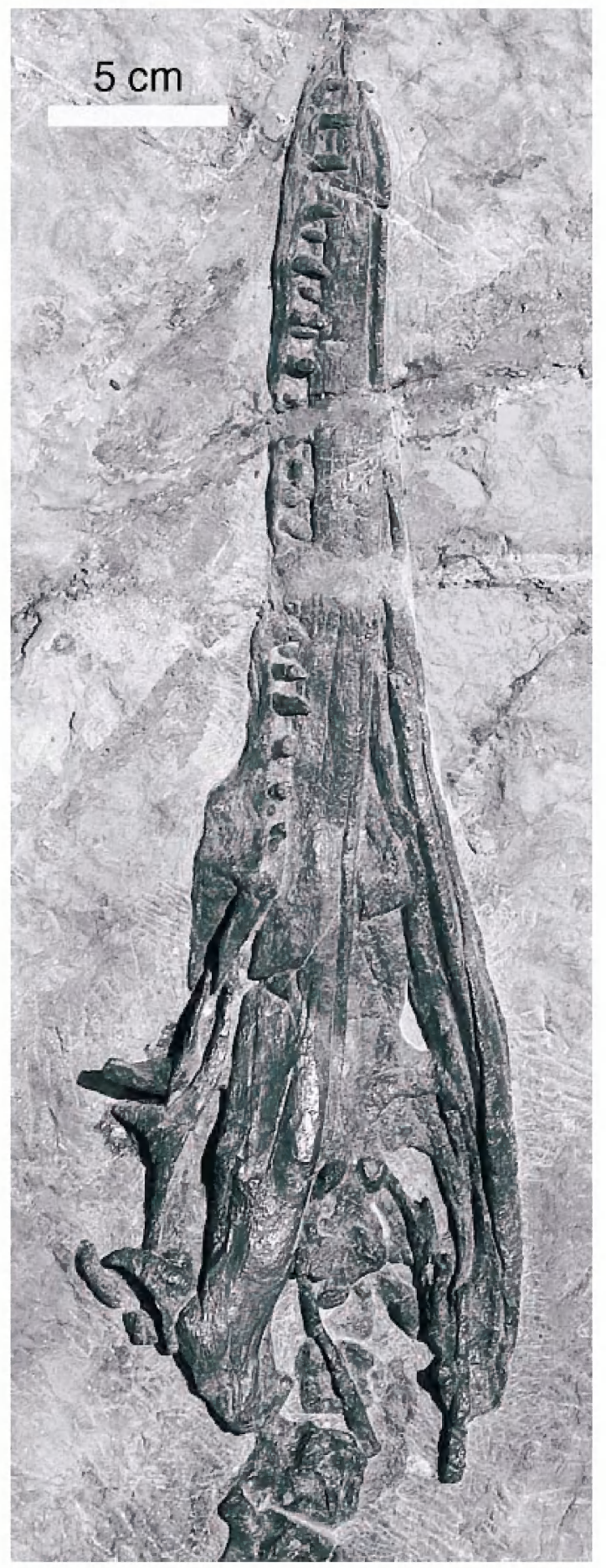

Fig. 2. Anshunsaurus huangguoshuensis, skull and lower jaw in ventral view (specimen no. IVPP V11834). nasals extend posteriorly to a level behind the anterior margin of the orbit as in Askeptosaurus.

\section{PREFRONTAL}

The triangular prefrontal, exposed in dorsal view, forms the anterodorsal (anteromedial) margin of the orbit. Its anteroventral margin meets the maxilla, its dorsal contact is with the frontal, and anteromedially it meets the nasal. The anterior tip of the prefrontal is rounded and short, whereas its posterior process, which extends along the dorsal margin of the orbit, is more prominently developed. Although the prefrontal closely approaches the postorbitofrontal along the dorsal (medial) margin of the orbit, the two elements remain separated from one another.

The prefrontals as described here are larger than indicated by Rieppel et al. (2000) as they extend further ventrally along the anterior margin of the orbit. The extension of the prefrontal equals that of the prefrontal plus the lacrimal in Askeptosaurus as described by Müller (2000, in press). Although the critical area is subject to some breakage, we conclude that a lacrimal is absent in Anshunsaurus.

\section{FRONTAL}

The paired slender frontals are exposed in dorsal view. Each of the frontals forms an anterolateral and an anteromedial process, both of which taper to a pointed tip; the anteromedial process of the frontal is longer than the anterolateral process. The anteromedial processes of the frontals, terminating slightly in front of the midpoint between the external nares and the orbits, together embrace the pointed posterior tips of the premaxillae. In Askeptosaurus (Müller, 2002, in press), the frontals reach forward to the level of the external naris, although they do not contact the external nares. The anterolateral processes of the frontals enter between the nasals and the prefrontals, extending forward not quite as far as the anterior tips of the nasals.

The paired frontals meet each other in a straight suture and they show a slight lateral expansion in their middle part between the orbits. The frontal is nearly excluded from 
the orbital margin by the prefrontal and postorbitofrontal. The frontal meets the postorbitofrontal in a straight suture. Each frontal forms a slender posterolateral process, which extends backward between the postorbitofrontal and parietal to a level narrowly behind the posterior margin of the pineal foramen. The posterolateral process of the frontal narrowly fails to contact the anterior tip of the supratemopral as in Askeptosaurus and in primitive dispsids generally. In its middle portion, the posterior end of the frontal meets the parietal bone in a complex interdigitating suture at the level of the postorbital arch. The suture with parietal remains unclear on the right side of the skull, however.

\section{POSTORBITOFRONTAL}

In contrast to Askeptosaurus, the postorbital and postfrontal are fused. The postorbitofrontal forms the posterodorsal (posteromedial) and most of the posterior margin of the orbit. Posterodorsally, the postorbitofrontal draws out into a long and slender process, which extends far back within the skull roof. It meets the mediolateral margin of the parietal between the frontal and supratemporal, and covers the anterior process of the squamosal dorsally. Its posterior end overlaps with the anterior end of the supratemporal. The tapering ventral process of the postorbitofrontal obliquely overlaps the dorsal process of the jugal within the postorbital arch.

\section{JuGAL}

Both jugals are exposed in dorsal, lateral, and ventral views. They are distinctly triradiate bones as in all other thalattosaurs. A long anterior (suborbital) process forms the ventral (lateral) margin of the orbit, meeting the posterior process of the maxilla. The pointed dorsal process enters the postorbital arch, partially defining the anterior margin of the lower temporal fenestra. The jugal of $A n$ shunsaurus is peculiar as it draws out posteriorly into a long and slender process that, at least to a large degree, closes the lower temporal fenestra ventrally. Although the posterior processes of both jugals is broken in the holotype, both symmetrically displaced anteromedially, they still seem long enough to have closely approached the quadrate in the articulated skull.

\section{PARIETAL}

The paired parietals are exposed in dorsal view. The bones meet each other in a straight dorsomedial suture. The parietal contacts the posterior process of the postorbitofrontal between the frontal and the supratemporal. The upper temporal fossa is completely obliterated. The parietals increasingly expand in a posterolateral direction, forming elongate supratemporal processes that form the posterior margin of the deeply excavated occiput.

The parietals enclose a large pineal foramen that is somewhat displaced anteriorly, located narrowly behind the frontoparietal suture. The size of pineal foramen differs in different specimens of Askeptosaurus (Müller, 2002, in press), but even in the largest specimen the pineal foramen is smaller than that in the holotype of Anshunsaurus (Müller, 2002).

\section{SUPRATEMPORAL}

The supratemporals are broadly exposed at the posterolateral corner of the skull table in dorsal view. They form relatively elongated slivers of bone. Anteriorly, the supratemporal is reduced to a narrow process, which extends anteriorly between the parietal and the postorbitofrontal. Ventrally, the supratemporals contact the squamosal, and possibly also the quadrate.

\section{SQuAmosal}

Both squamosals have been pushed out laterally during fossilization, and hence expose their lateral side in the dorsal view of the specimen. They are hockey-stick shaped and generally slender. The squamosal consists of two processes, an anterior one and a ventral one. The anterior process follows the lateral margin of the skull table, participating in the formation of the upper margin of the lower temporal fenestra, underlapping the posterior process of the postorbitofrontal. It tapers to a pointed tip at a level ahead of the posterior margin of the parietal foramen. The ventral process is much elongated and slightly recurved. It must have lined the lateral 
edge of the posteriorly concave shaft of the quadrate, extending to the ventral margin of the cheek and closely approaching the posterior tip of the jugal. The posterior process of the jugal must have closely approached the ventral tip of the squamosal in the articulated skull.

\section{QUADRATE}

Both quadrates are preserved in articulation, but they are partially obscured by neighboring skull elements in both specimens due to the dorsoventral compression of the skull. The quadrate is a relatively large and robust element with a distinctly thickened shaft but thinning along the margins. The cephalic condyle is located near the ventrolateral margin of the parietal table, suspended in life from the squamosal and supratemporal. In dorsal view, the right quadrate shows an anterior process extending from the medial margin of the cephalic condyle. It must represent the dorsal margin of an extensive anterior quadrate flange, which is also known in other thalattosaurs. The medial lamina is fan shaped and thinner to border. The mandibular condyle is hidden by the lower jaw.

\section{SCLERAL OSSICLES}

No scleral ossicle is observed in these specimens.

\section{VOMER}

Only the posterior part of the vomers is exposed in palatal view. Their preservation suggests that they are slender and elongate elements. A clear groove separates the paired vomers from one another (the vomers are fused in Askeptosaurus; Müller, 2002, in press). The pterygoids enter between the posterior parts of the vomers, thus separating the two palatines from one another. A concave area lies behind the vomers, lateral to the pterygoid and anterior to the palatine; this depression would have been part of the choana (internal naris). There is no indication of teeth on the vomers.

\section{PALATINE}

The palatines are poorly known; their shape cannot be determined. The two pala- tines are separated along the ventral midline of the skull by the contact of the vomers with the pterygoids. The way that the palatine enters the internal naris remains unclear, as does the general shape of the choana. Posteriorly, the palatine forms the anterior margin of a large suborbital fenestra, but the arrangement of the palatal elements around the lateral and posterior margins of this fenestra remain unclear. There are no palatine teeth.

\section{PTERYGOID}

The pterygoids are well preserved and exposed in ventral view. They are large elements, meeting anteriorly in front of the narrow interpterygoid vacuity along the midline of the skull and becoming progressively narrower as they approach their contacts with the vomers. The length of the plate ramus is nearly twice the length of the quadrate ramus. The transverse process of the pterygoid is conspicuous but partially obscured by the lower jaw and the left hyoid; the suture with the ectoperygoid cannot be observed. The pterygoid contributes to the medial and posterior margins of the suborbital fenestra, but its exact contribution to this opening could not be determined. A low but sharp crest projects ventrally from the corner between the transverse process and the quadrate ramus, extending into the posterolateral direction. This crest extends backward to a level in front of the articulation of the pterygoid with the basipterygoid process. It must have served as a site of origin for parts of the pterygoideus muscle. Posteriorly, the pterygoid tapers significantly and forms the quadrate ramus. The quadrate ramus carries a distinct, ventrally projecting flange. The quadrate rami of the pterygoids diverge posteriorly as they extend backward from the palatobasal articulation, enclosing an acute angel of about $60^{\circ}$. The posterior part of the right quadrate ramus is obscured by overlapping skull elements, but the left one is complete and is applied to the medial side of the quadrate; the posterior tip of the pterygoid must have formed a medial contact with the quadrate just above the mandibular condyle. The transverse process and quadrate ramus of the pterygoid flange define the anteromedial and 
medial margin of the large subtemporal fenestra. There are no pterygoid teeth.

\section{ECTOPTERYGOID}

The ectopterygoid is mostly obscured by the lower jaw.

\section{PARABASISPHENOID}

This element is formed by the fusion of the dermal parasphenoid to the ventral surface of the basisphenoid. It is only exposed in ventral view. Anteriorly, the bone appears to extend into a long and narrow cultriform process that entered the narrow interpterygoid vacuity. As preserved, the cultriform process appears to lie close to the left pterygoid, with its anteriormost portion obscured from ventral view. The base of the cultriform process is slightly expanded. Two prominent drop shaped ventral expansions lie posterolaterally to the base of the cultriform process, representing the basipterygoid processes. Between them, two slender grooves extend in a posterolateral direction, lined by small medial crests. These grooves represent the ventrally open Vidian or parabasal canals that carry the internal carotid artery as well as the palatine branch of the facial nerve. A foramen located close to the posteromedial edge of the basipterygoid processes served as entry foramen for the cerebral branch of the internal carotid, as it has also been described for Askeptosaurus (Müller, 2002, in press). The ventral surface of the parabasisphenoid shows a shallow triangular depression that extends to the posterior edge where the bone meets the basioccipital. Posterolaterally, the parabasisphenoid is drawn out into two prominent projections. They are broad and with a relatively sharp distal tip, originally underlying the fenestra vestibuli. The suture between the parabasisphenoid and the basioccipital is not very clear in the middle part of the basicranium, but the basisphenoid tubercle is not fused with the pronounced basioccipital tubercle.

\section{BASIOCCIPITAL}

The basioccipital is again only exposed in ventral view. It is a broad element with a more or less trapezoid shape similar to that seen in Askeptosaurus (Müller, 2002, in press). Anteriorly, the basioccipital meets the parabasisphenoid in what appears to be an undulating suture. In its anterolateral part, the basioccipital bears prominent knoblike structures, the basal tubera. They are ventrolaterally directed, their medial surface being oblique and their lowermost tips forming semilunar edges. The middle portion of the ventral surface of the basioccipital is depressed. More posteriorly, the basioccipital shows a ventral expansion with a slightly convex posterior edge. This expansion represents the contribution of the basioccipital to the formation of the occipital condyle. Laterally, the basioccipital bears a prominent concave facet between the posterior margin of the basal tubera and the anterolateral edge of the posteroventral expansion. The facet serves for the contact of the proximal end of the opisthotic.

\section{SUPRAOCCIPITAL}

The supraoccipital is only partially exposed in dorsal view. It is seen to project from below the posterior margin of the parietals, carrying a low sagittal crest.

\section{Prootic}

The anterior of the part right prootic is exposed in palatal view, whereas its posterior part is coved by the quadrate. It contacts the lateral margin of the parabasisphenoid, positioned between it and the medial margin of the quadrate process of the pterygoid.

\section{OPISTHOTIC AND EXOCCIPITAL}

The right opisthotic is well exposed in ventral and dorsal view. This bone is fused with the exoccipital and forms the well-developed paroccipital process. Its medial head articulated with the concave facet of the basioccipital described above. Its posterior margin is exposed below the supraoccipital and the parietal in dorsal view.

\section{STAPES}

No stapes can be identified.

\section{LOWER JAW}

The lower jaws are mainly exposed in lateral view, with only a small portion of the 
medial side exposed. The slender mandibular ramus has an elongated and straight toothbearing portion, whereas the posterior part is comparatively short and slightly curved. There is no true retroarticular process.

\section{DENTARY}

The dentary is the longest element in the lower jaw. It is straight and becomes increasingly expanded posteriorly. It covers the anterior lateral portion of the mandibular ramus, but the splenial could also have been exposed in lateral view. Two dentaries meet anteriorly along approximately one-third of their entire length, forming an elongated mandibular symphysis together with the splenials. The mandibular symphysis of dentaries tapers to a narrow tip anteriorly. Posteriorly, the dentary bifurcates into a short posterodorsal and an elongated posteroventral process, both terminating in a pointed tip. The posterodorsal process overlaps part of the lateral surface of the surangular; the remaining posterior margin of the dentary contacts the surangular and the angular. The alveolar margin of the dentary is covered by the skull; only four conical teeth are observed in the holotype.

\section{SPLENIAL}

The splenial is only exposed in ventral view. It is an elongated element located anteroventrally, but its posterior end reaches the position of the coronoid process, leveling with the anterior border of the supratemopral fenestra. Its anteriormost portion contributes to the formation of the symphysis. The splenial forms the ventral margin of the lower jaw ramus in front of the angular and below the dentary.

\section{CORONOID}

The coronoid can only be identified on the lateral side of the right mandible of specimen IVPP V11834. Given uncertainties about the detailed sutural contacts, two alternative interpretations obtain. In the first interpretation, the coronoid is an elongated element, meeting the dentary anteriorly and the surangular posteriorly. In the second interpretation, it is shorter and in contact with the surangular only, albeit in a pattern that is comparable to other thalattosaurs. For that reason, we prefer the latter of the two interpretations. The general shape of the coronoid is that of an elongated triangle with a moderately developed coronoid process. This bone might also be exposed under the orbit in holotype, but this is difficult to ascertain.

\section{ANGULAR}

The angular is a relatively elongated bone, defining the ventral margin of the posterior part of the mandibular ramus. Anteriorly, it borders the dorsal edge of the posteroventral dentary process. The straight dorsal margin of the angular meets the surangular along its entire length. Posteriorly, the angular is slightly curved dorsally and shows a tapering end, which contacts the prearticular on the ventral side, level with the anterior border of the articular.

\section{SURANGULAR}

The surangular covers the posterodorsal part of the lower jaw ramus. It also is an elongated element. Anteriorly, it meets both the posterior processes of the dentary; its anterodorsal margin supported the coronoid. Posteriorly, the surangular closely approaches the posterior end of the lower jaw, terminating in a contact with the articular. Only a short part of the surangular participates in the formation of the ventral margin of the lower jaw.

\section{PREARTICULAR}

The prearticular would be restricted to the medial side of the posteroventral part of the mandibular ramus, but it gained lateral exposure due to the deformation of the lower jaw. Its ventral margin contacts the angular and the surangular; posterodorsally, it contacts the articular.

\section{ARTiCULAR}

The articular expands over the whole width of the posterior end of the lower jaw, covering the entire dorsal surface of the lower jaw between the prearticular and the surangular. There are no signs of fusion of the articular with the prearticular. The foramen 
for the chorda tympani lies close to the suture with the surangular.

\section{HYOID}

A pair of slender hyobranchial elements, identified as first ceratobrachchials, are preserved in both specimens and exposed in ventral view. The position of ceratobranchials is similar in two specimens, that is, to the lateral side of the quadrate. The left hyoid partially covers the transverse process of the pterygoid, the subtemporal fenestra, and the ventral margin of the lower jaw; the right one is pushed against the paroccipital process and extends backward to the third cervical vertebra. The hyoid is constricted in its middle part, with slightly expanding anterior and posterior ends.

\section{AXIAL SKeleton}

Anshunsaurus bears at least 38 presacral, 2 sacral, and more than 50 caudal vertebrae (figs. 3-7). The 35th presacral vertebra is represented by part of the neural spine only in the holotype (fig. 5), and it is separated from the succeeding one by a narrow gap, such that the number of presacral vertebrae might be 39 . The cervical vertebrae are exposed in both specimens, but the dorsal vertebrae are completely concealed by the gastral ribs in IVPP V11834, and only a few caudal vertebrae are observed in the holotype.

\section{Cervical Region}

Müller (2002, in press) used the morphology of the ribs to demarcate the cervical from the dorsal region in Askeptosaurus, and the same method also is used here. The number of the cervical vertebrae is at least 15, because the 15 th vertebra still is articulated with a double-headed rib in the holotype. It is difficult to assess whether the 16th vertebra, located immediately in front of the clavicle, is the last cervical or first dorsal because it is incompletely preserved in the holotype

$\rightarrow$

Fig. 3. Anshunsaurus huangguoshuensis, specimen no. IVPP V11834.

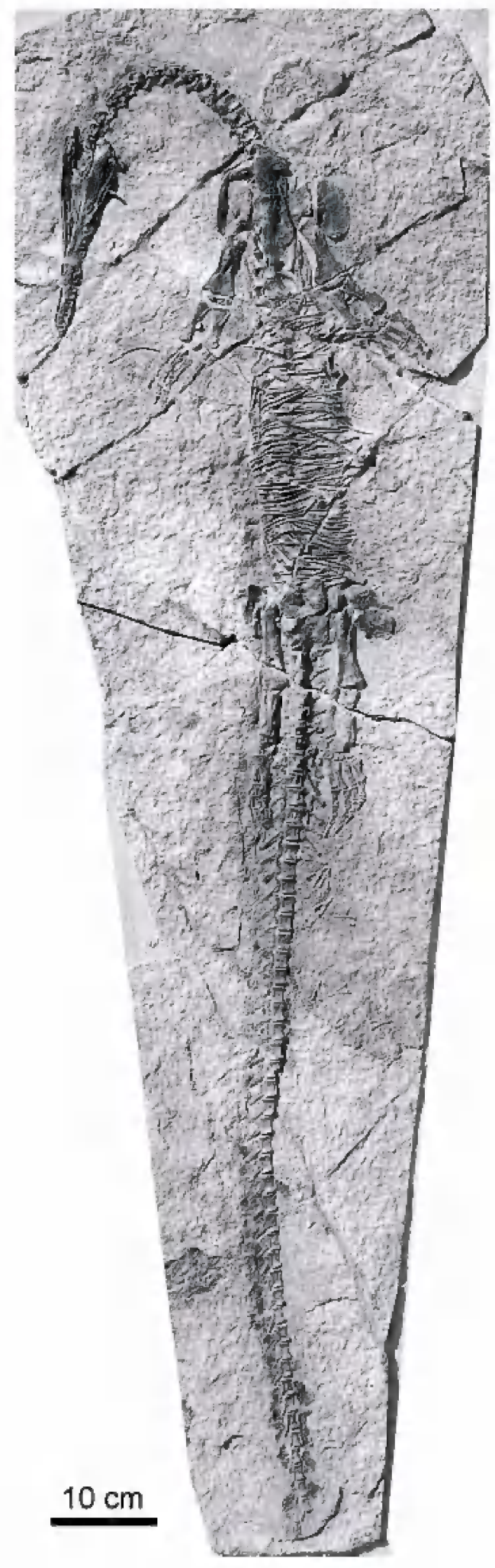



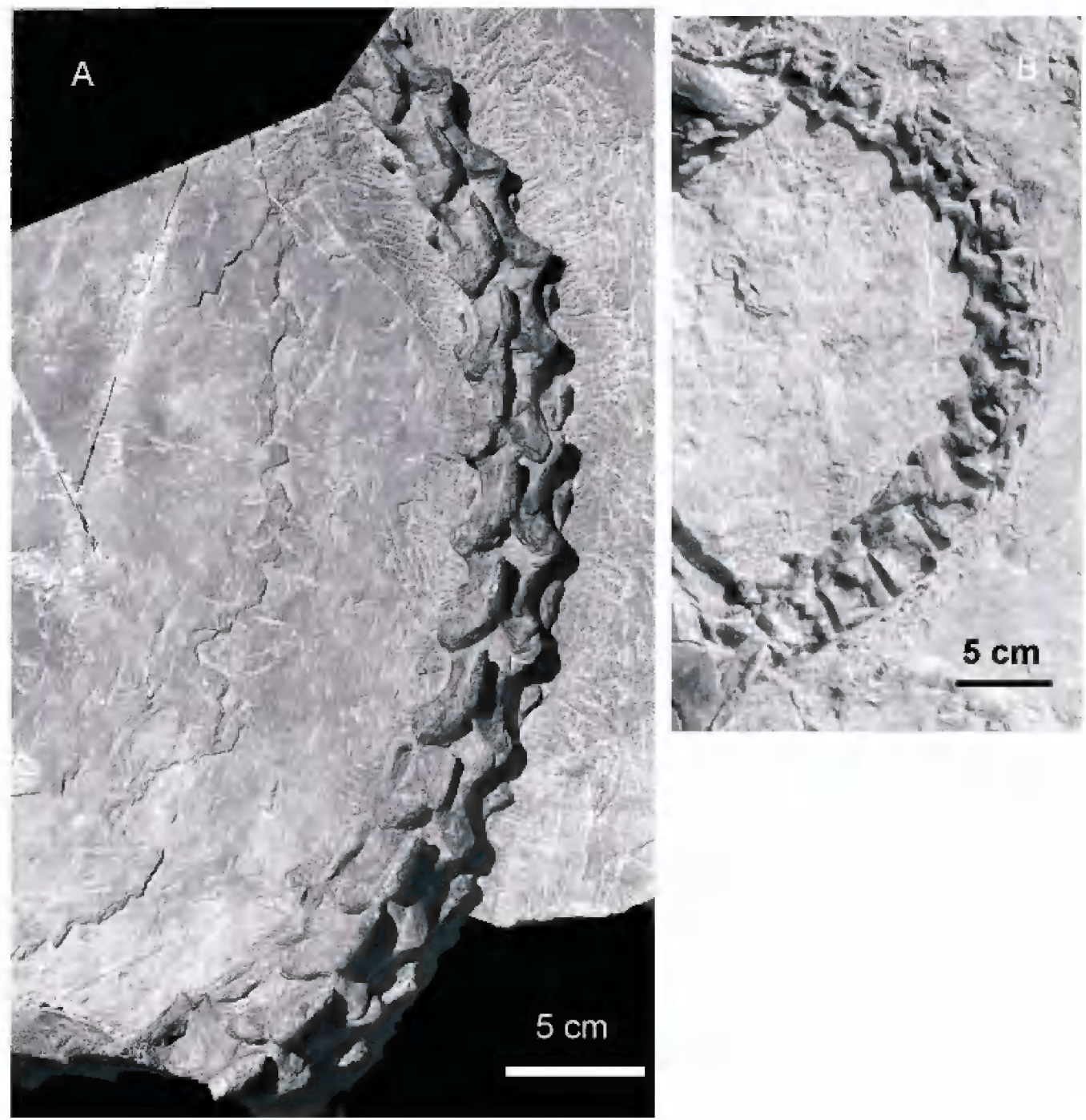

Fig. 4. Anshunsaurus huangguoshuensis, cervical vertebrae (A) in dorsal view (specimen IVPP V11835-2) (B) in lateral view (specimen IVPP V11834).

and concealed in specimen IVPP V11834. The length of the cervical region is $49 \mathrm{~cm}$ in the holotype. Almost all the cervical vertebrae in the holotype are exposed in dorsal view, but the atlas, axis, and the $3 \mathrm{rd}$ and 14 th to 16 th vertebrae are also prepared in ventral view; in IVPP V11834 the cervical vertebrae are exposed in right lateral view.

The relationship of the various components of the atlas-axis complex can be observed in ventral view in the holotype. The atlas is ring shaped to match the outline of the occipital condyle. A pair of cervical ribs articulates with the lateral aspect of the atlas. The intercentrum is of roughly rectangular shape in ventral view. The morphology of the atlas neural arch remains uncertain. A vertebral element that lies posterior to the intercentrum, and appears to project dorsal beyond the latter, is identified as the first (atlas) centrum. It is a half-saddle-shaped bone with clear margins setting it off from neighboring anterior and posterior elements. This bone seems not to be preserved in Askeptosaurus. Kuhn (1952) noted a possible centrum lying anteriorly to the atlas neural arches, but it is 


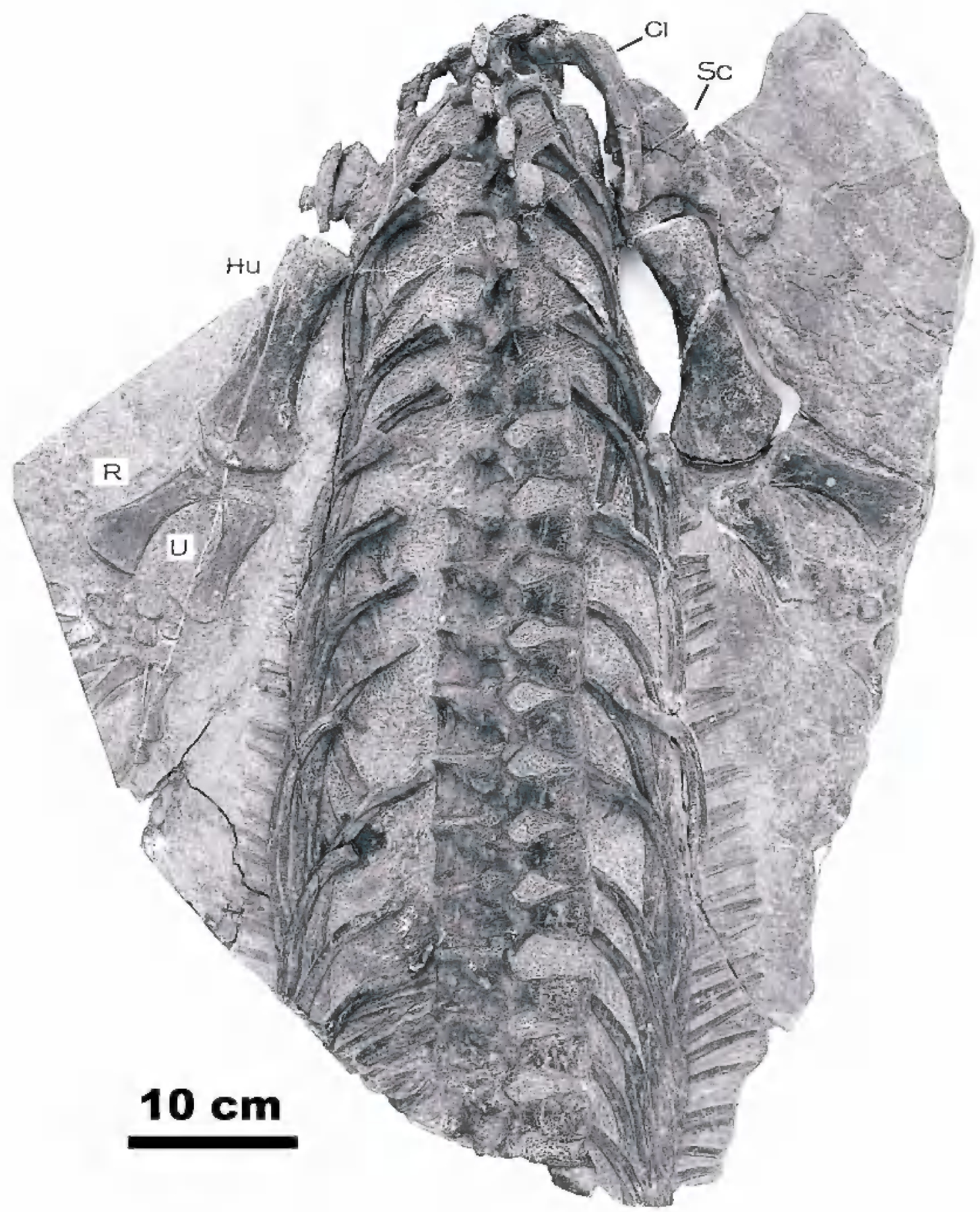

Fig. 5. Anshunsaurus huangguoshuensis in dorsal view (specimen IVPP V11835-3). See appendix 1 for anatomical abbreviations. 


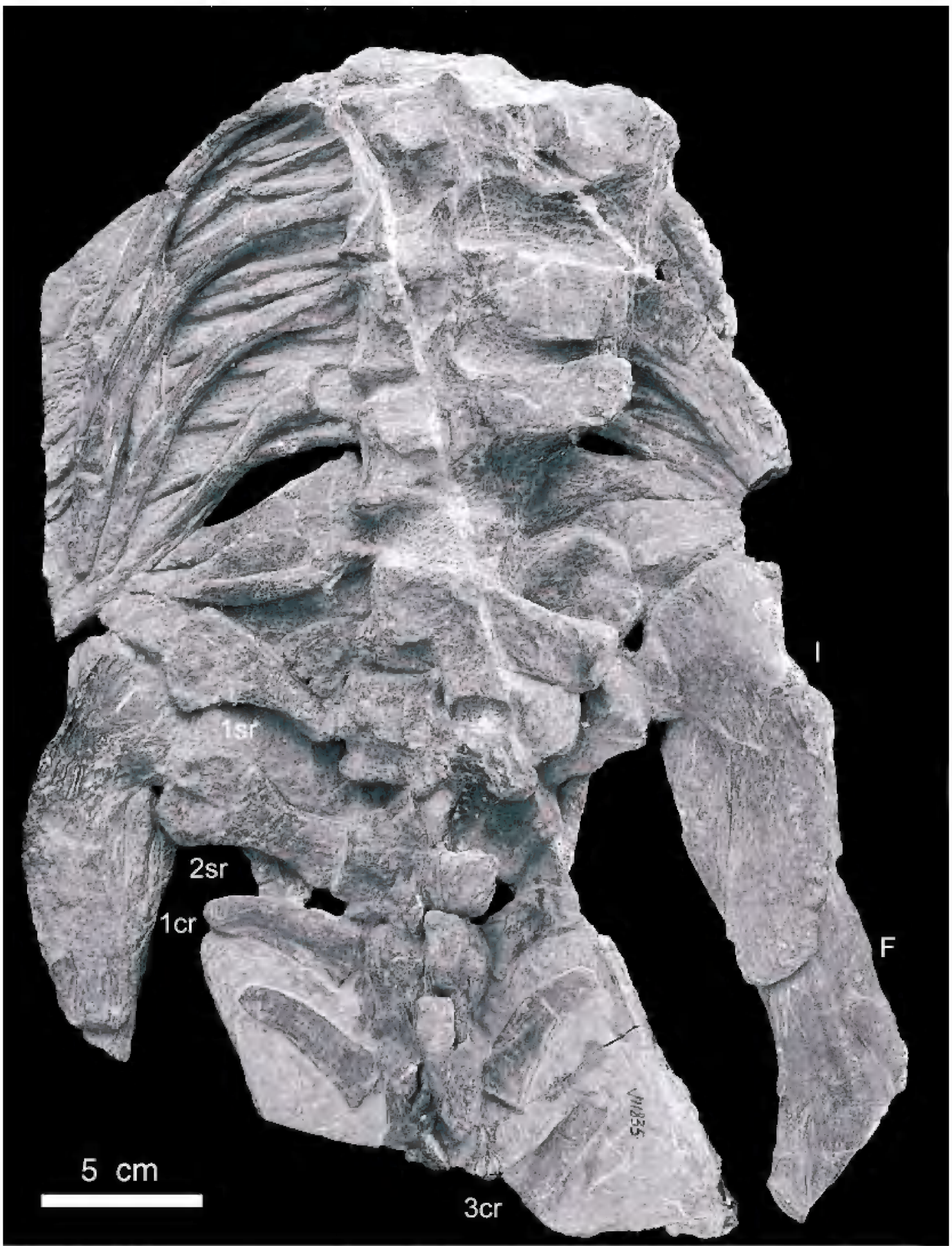

Fig. 6. Anshunsaurus huangguoshuensis in dorsal view (specimen IVPP V11835-4). See appendix 1 for anatomical abbreviations. 


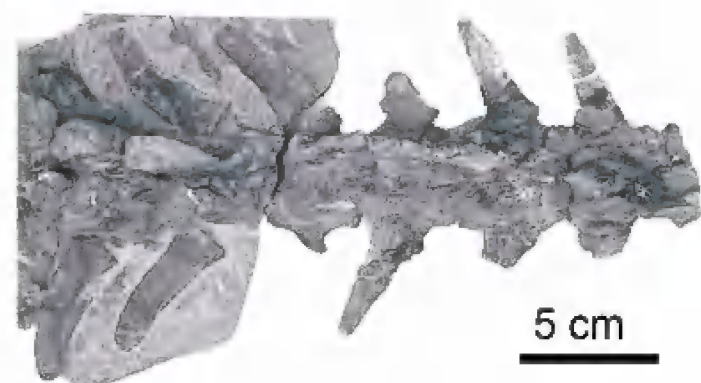

Fig. 7. Anshunsaurus huangguoshuensis, anterior caudals (IVPP $11835-5$ and part of IVPP V 11835-4) in dorsal view.

determined to be a broken part of the braincase (Müller, 2002). The proatlas, which was reported in Askeptosaurus (Müller, 2002, in press), cannot be identified in Anshunsaurus.

The axis is a prominent, elongated element. The axis centrum is longer than high, and shows a distinctly longitudinal keel extending along the midline of its ventral surface. A pair of double-headed ribs articulates laterally. The neural arch of the axis shows weakly developed pre- and postzygapophysis. The neural spine is low and distinctly elongated; its dorsal margin is straight.

The remaining cervical vertebrae are rather small elements carrying a relatively low neural spine. They slightly increase in size in an anteroposterior direction. The centrum is slightly constricted in its central part and generally longer than high. It may show a semilunar depression on its ventrolateral aspect that faces ventrally. A distinct ventral keel is present on the third centrum, which in the last few cervicals is reduced to a faint ridge. The remaining lateral part of the centrum consists of a concave curvature.

The base of the neural arch of the cervical vertebrae forms relatively stout pre- and postzygapophyses. The prezygapophyses are somewhat more prominently developed, and cover the postzygapophyses in lateral view (fig. 4). They show a broad base, and whereas the prezygapophyses face dorsomedially, the postzygapophyses taper only slightly in a posterior direction and are nearly horizontally orientated. The neural spine is of roughly rectangular shape. The length and the height of the neural spine show some increase from the 3 rd to the 16 th vertebra.
Müller (2002, in press) identified paired rib articulations on the cervical vertebrae of Askeptosaurus, comprising a diapophysis for the tuberculum and a parapophysis for the capitulum. The diapophysis lies directly below the neural arch on the dorsalmost part of the centrum, more or less in the middle of the vertebra, and it consists of an irregularly rounded or rectangular depression. The parapophysis is located on the central aspect of the centrum and is somewhat more posteriorly directed than the diapophysis. In Anshunsaurus, only a diapophysis with the same shape and position as seen in Askeptosaurus can be identified on the cervicals, but no parapophysis (fig. 4). The capitulum articulated with the anteroventral aspect of the centrum. This position is close to the original position of the intercentrum, which may be the reason why Kuhn (1952) suggested that the capitulum articulated with a cartilaginous intercentrum in Askeptosaurus.

The cervical ribs articulate with vertebrae beginning with the atlas. It remains unknown whether the ribs articulating with the atlas are dichocephalous or holoceophalous. They form a small and slender rod of bone with a slightly expanded anterior head, tapering in a posterior direction and terminating in a sharp tip. Dichocephalous cervical ribs are preserved in articulation with the axis and the 3 rd and 15 th cervical in the holotype, and from the 3rd to the 10th cervical in V11834. The dorsal tuberculum is broader than the ventral capitulum. The cervical ribs become increasingly more elongated posteriorly. The posterior ends of the third, the fourth, and the fifth ribs do not project beyond the posterior margin of the respective centrum, whereas more posterior ribs overlap with the anterior margin of the succeeding centrum.

\section{DORSAL REGION}

In specimen V11834, the vertebrae of the dorsal region are almost completely concealed by the ribs and gastralia, such that the following description is mainly based on the holotype. The vertebrae expose their dorsal to lateral side from anterior to posterior. The number of dorsals is minimally 23 . No intercentra are identified in the dorsal region.

The length of the centra is fairly constant 
throughout the dorsal region, with just the anteriormost vertebrae being slightly smaller. The length of the centrum ranges from 33 $\mathrm{mm}$ to $36 \mathrm{~mm}$ (with an average of about 35 $\mathrm{mm}$ ). All dorsal vertebrae are larger than any of the cervicals, mainly as a result of the dorsal extension of the neural spine. The synapophysis is anteroventrally directed, originating in the midventral region of the neural arch and then extending down to near the anterior margin of the centrum (figs. 5, 6). The attachment site develops into a prominent process anteriorly, and posteriorly is reduced to a small knob. The centrum is generally longer than high, its middle part being slightly constricted.

The neural arch is relatively long and fully fused with the centrum. The prezygapophyses are anteromedially directed. Their dorsal edge is unusually straight, whereas the distalmost margin is slightly recurved dorsally. The postzygapophyses are distinctly shorter and not as broad as the prezygapophyses, but the dorsal recurvation of the distalmost tip is distinct as well. Below the zygapophyseal articulation between the succeeding vertebrae lie the distinct intervertebral foramens with distinct triangular outline. The neural spines are broad and trapeziform in shape, expanded in the dorsal direction. They are more or less vertically oriented. The last few neural spines are relatively narrow and higher than the preceding ones.

All the dorsal vertebrae bear ribs, including the vertebrae immediately preceding the sacrum; there is no true lumbar vertebra. The morphology of the dorsal ribs differs distinctly from that of the cervical ribs. The proximal head of the dorsal ribs is holocephalous and slightly expanded. With the exception of the posteriormost ribs, all dorsal ribs are similar in size (about $16 \mathrm{~cm}$ in length) and notably longer than the cervical ones. All ribs are strongly curved and show a slight distal expansion. The last four dorsal ribs decrease abruptly in size, with the last two dorsal ribs being the shortest; they are slender and point almost straight laterally.

A series of gastralia is partially exposed below ribs in the holotype, whereas they are well exposed in IVPP V11834 in ventral view, in the area between the pectoral and pelvic girdle. Gastralia can only be observed behind the 24th vertebra in the holotype and behind the posterior tip of the interclavicle in IVPP V11834. They appear to be slender elements, being slightly expanded medially and tapering laterally. Both halves overlap each other in the ventral midline of the body. More than 35 and 50 pairs of gastralia are preserved in the holotype and IVPP V11834, respectively, indicating the presence of one pair of gastral ribs per body segment.

\section{SACRAL REgION}

Two sacral vertebrae are present in $\mathrm{An}$ shunsaurus (fig. 6). There is no sign of any fusion between the vertebrae, nor do the sacral ribs fuse to the centra or the neural arches. The sacral vertebrae are similar in shape to the preceding dorsals, but the length of the centrum of the sacral vertebrae is somewhat longer than that of the dorsal vertebrae, and the neural spines are reduce in height. The sacral rib meets the vertebra in the lower half of the centrum.

The sacral ribs are not fused to the sacral vertebra. They are expanded, especially the distal portion, and fan shaped, contacting the ilium with their distal margin. The left sacral ribs measure $57 \mathrm{~mm}$ (anterior) and $59 \mathrm{~mm}$ (posterior) in length, $32 \mathrm{~mm}$ (anterior) and $35 \mathrm{~mm}$ (posterior) in width of the distal end, and $12 \mathrm{~mm}$ (anterior) and $23 \mathrm{~mm}$ (posterior) in width of the proximal end.

\section{Caudal Region}

Only the anteriormost six caudal vertebrae are preserved in the holotype (fig. 7), whereas 50 are exposed in lateral view in IVPP V11834 (fig. 3). The anterior caudal vertebrae bear ribs, which do not fuse with the vertebra in the anterior six caudals. The articular facet for the ribs represents a halfrounded lateral depression on the centrum. Where the ribs are fused with the vertebrae, they appear like transverse processes; more posteriorly, the causal ribs abruptly reduce to a small knob and completely disappear from the 12th caudal onward. In more posterior caudals, where no ribs attach, the centra show a vertical depression in the mid region, running from the ventrolateral margin up to the dorsal edge, in an otherwise smooth lateral surface. 
The length of all centra is relatively constant within the caudal region, around $32 \mathrm{~mm}$ in IVPP V11834. However, the height of the centra gradually decreases in an anteroposterior direction. In the anterior caudals, the centrum appears square in lateral view, as its length approximates its height. More posteriorly, the centra become relatively slender as their height decreases.

The neural arches in the anterior caudals are relatively similar to the condition of the dorsals. They are comparatively high and with stout pre- and small postzygapophyses. The neural arches of the more posterior caudals differ in many respects. The ventral base is not that high, and almost directly above the contact to the centrum the prominent prezygapophysis originates. It is distinctly more elongated than in the anterior portion of the tail and is anterodorsally directed. Conversely, the postzygapophysis remains very small, representing only a small, posterolaterally projecting triangle.

The neural spines are not as broad as the dorsal neural spines; rather they only reach two-thirds of the width of the latter at maximum. The neural spine becomes increasingly shorter in the middle and posterior portion of the tail. Furthermore, they become more slender and the orientation changes from more or less dorsal to posterodorsal.

Beginning with the fourth caudal (figs. 3, 7), haemal arches are present between vertebrae. No haemal arch contacts with the centra behind of the 13th caudal, and most haemal arches are not preserved in IVPP V11834. The haemal arch contacts both centra but only articulates with the posteroventral margin of the preceding centrum. The haemal arches are posteroventrally directed and $\mathrm{V}$ shaped, with the dorsal end being distinctly expanded. The two dorsal knoblike tips show small articulation surfaces, whereas the ventral tip of the arch is elongated and rectangular in shape.

At least six pairs of caudal rib are present in Anshunsaurus. The border between the ribs and the vertebrae is clear even if some ribs seem to fuse to the vertebrae. The first two pairs of ribs in the proximal caudal region are short and broad, but taper distally, showing a posterior recurvation. The ribs decrease in size from front to back. In the ho- lotype, the following ribs are more tapering into the distal direction, and their straight margins form a triangular shape in dorsal view. In IVPP V11834, all these caudal ribs show more or less recurvation and less tapering. They are generally slender. All caudal ribs point anterolaterally.

\section{Pectoral Girdle}

The elements of the pectoral girdle are prepared mainly from the ventral (lateral) side. The shoulder girdle is preserved in situ in the holotype but is slightly dislocated in IVPP V11834. It consists of interclavicle, clavicles, coracoids, and scapulae. In the holotype, the interclavicle is almost complete other than the left side of the crossbar; two incomplete clavicles are exposed in dorsal view; two nearly complete coracoids are preserved in situ; scapulae are fragmentary (fig. 8). In IVPP V11834, all elements of the girdle except the left clavicle are completely preserved and close to their original position, and the left scapula is exposed in dorsomedial view (fig. 9).

\section{INTERCLAVICLE}

The interclavicle is a T-shaped, elongated element of flattened appearance. Its crossbar is crescent shaped; the anterior tip is rounded and rostrally directed; the lateral processes taper into the posterolateral direction. Two lateral processes are not symmetric. These lateral processes are stronger than those in Askeptosaurus. Their anterior margin is slightly depressed for the contact with the back edge of the clavicles. The posterior process is the main body of the interclavicle; its caudal elongation is about two times as long as the crossbar. There is no tapering into the posterior direction until the distal tip ends in a sharp angle in the holotype. The distal tip in IVPP V11834 is broken and partly covered by ribs. In contrast, the distal tip appears to be broad and rounded in Askeptosaurus.

\section{Clavicle}

The clavicle is a thin, slender, rodlike element, which is significantly recurved into an anterolateral direction. It can be divided into two parts: the anterior part that articu- 


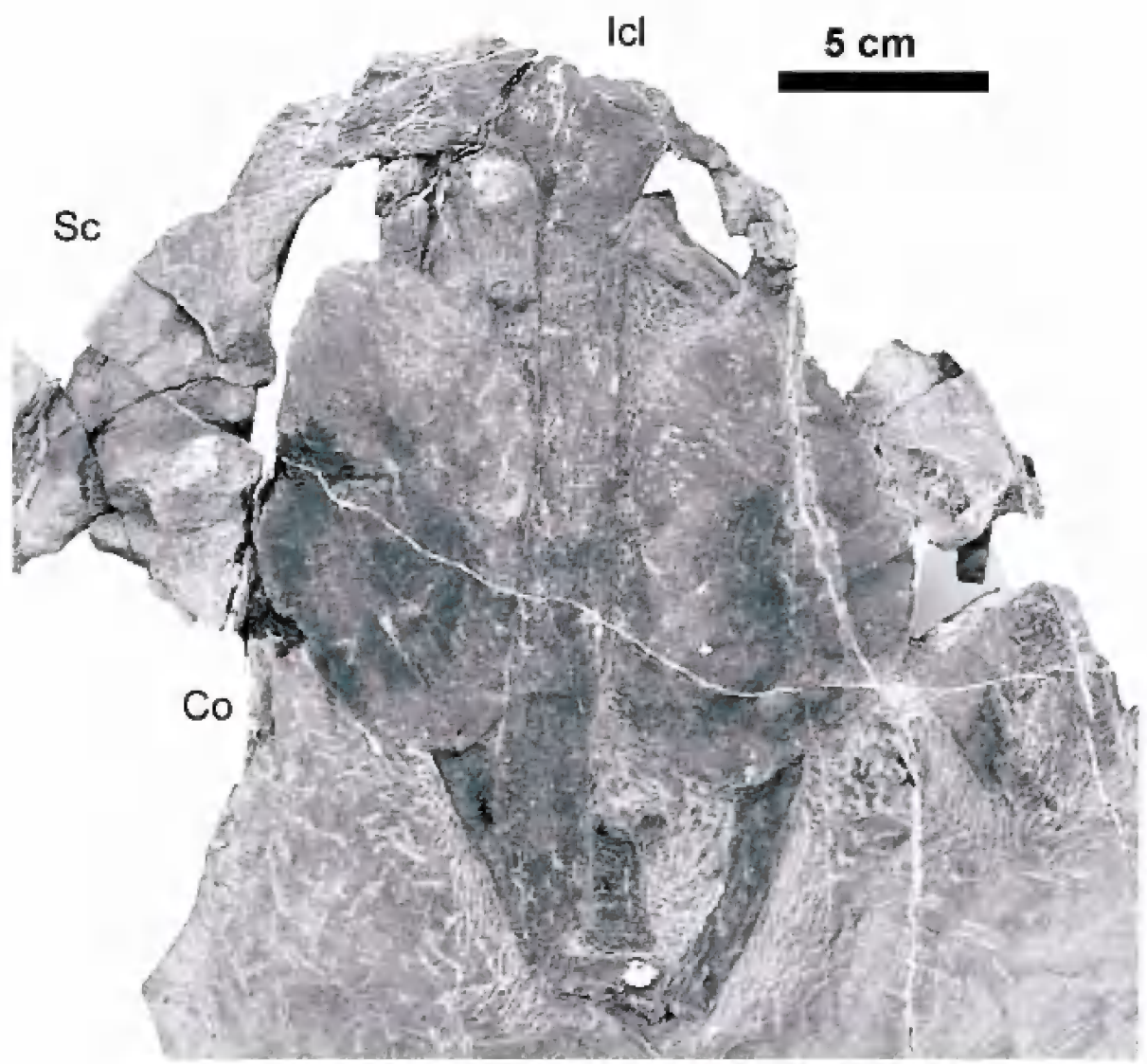

Fig. 8. Anshunsaurus huangguoshuensis, pectoral girdle in ventral view (specimen IVPP 11835-3). See appendix 1 for anatomical abbreviations.

lates with the interclavicle and the posterior part that does not. The proximal and the distal portions enclose an angle of about $120^{\circ}$, which is more pronounced than that in Xinpusaurus (Liu, 2001). The anterior part is slightly narrower than the posterior part in ventral view, whereas the width of the entire posterior part is nearly the same. This is different from the thinning backward in the posterior part of this bone in Askeptosaurus. The anterior part is markedly shorter than the posterior one.

The concave edge of the clavicle, rather than the convex edge, articulates with the interclavicle (fig. 9). The same should be true for the articulation with the scapula. In the reconstruction of the pectoral girdle in $A s$ keptosaurus (Müller, 2002: fig 18), the author followed Kuhn-Schnyder (1952, 1960) to position the clavicles curving to the pos- terior; as a result the convex edge of the clavicle contacts the interclavicle. If this is the right reconstruction, these two animals are quite different in this structure. However, the similar situation as in Anshunsaurus also is observed in specimen PIMUZ T4842 of Askeptosaurus, so the relationship of the interclavicle and the clavicle in Askeptosaurus could be the same as described here in Anshunsaurus. The contact area for the interclavicle looks fixed in Anshunsaurus.

\section{SCAPULA}

The scapular blade is a broad, low structure, as is the case in Askeptosaurus. Its anterior margin is narrow and convex. Its dorsal margin is broad and only slightly convex. The clavicle perhaps contacts only the dorsal margin of the scapula, not the anterior mar- 


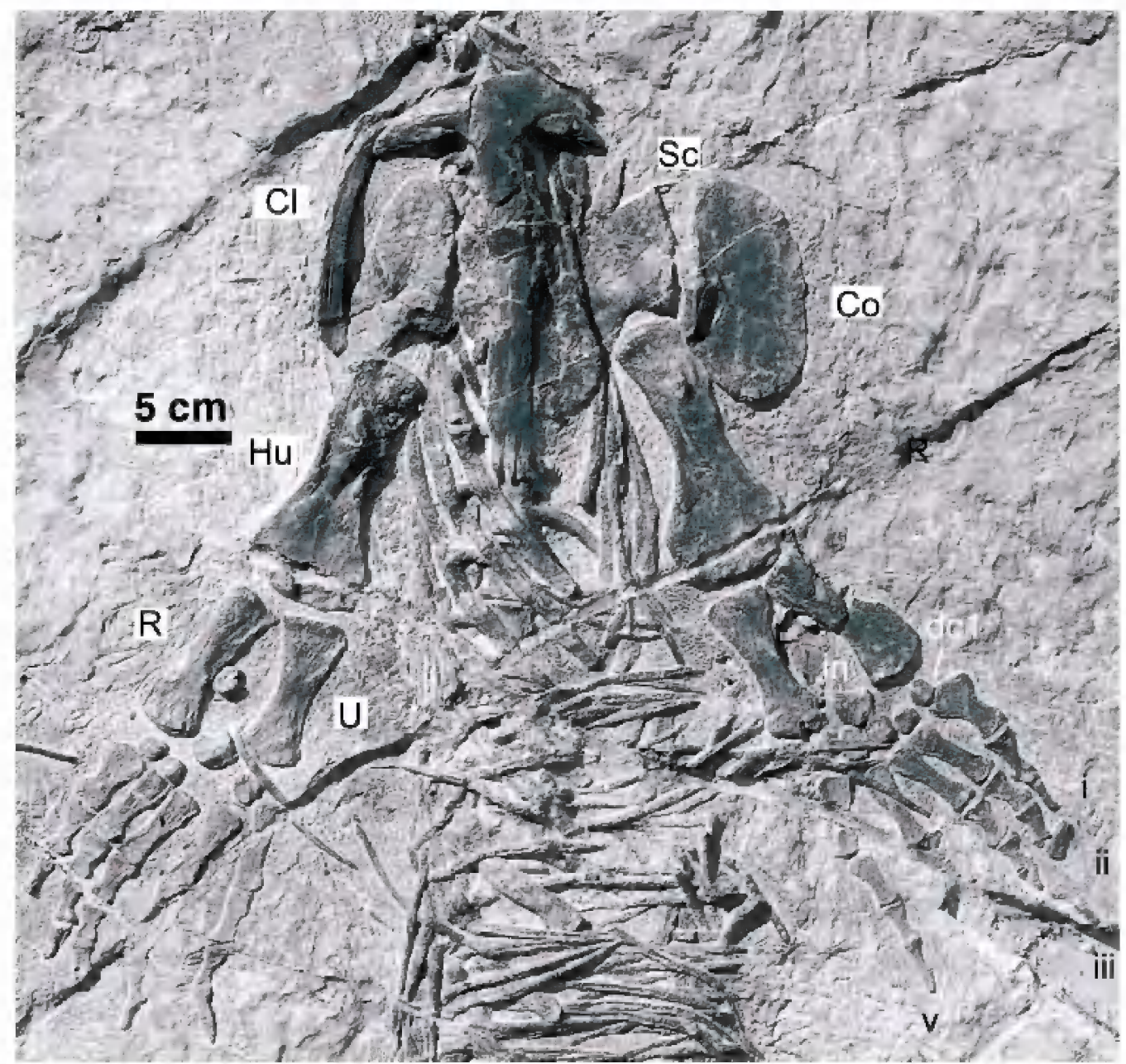

Fig. 9. Anshunsaurus huangguoshuensis, pectoral girdle in ventral view (specimen IVPP V11834). See appendix 1 for anatomical abbreviations.

gin as in Askeptosaurus. Its posterior margin is strongly concave. The posteroventral portion of the bone is thickened and forms the dorsal part of the glenoid region. The ventral margin is slightly convex, corresponding to the morphology of the dorsal edge of the coracoid, to which it is sutured.

As mentioned by Liu (2001), there are two different types of scapulae in Thalattosauria: one type that is seen in Thalattosaurus, Nectosaurus, and Xinpusaurus and another type characteristic of Askeptosaurus, Clarazia, Hescheleria, and Anshunaurus. These two types can also be found in the Ichthyopterygia (Motani, 1999). The function of these shape types is still unknown.

\section{CORACOID}

The coracoid is a broad and somewhat parallelogram-shaped bone. The left coracoid is incomplete in the holotype. Its lateral (dorsal) margin is slightly convex and loosely articulated with the scapula with a pointed anterolateral (anterodorsal) corner. The medial (ventral) margin is covered by the interclavicle, so its exact shape is unclear. The posteroventral part extends posteriorly to the glenoid cavity. The coracoid foramen cannot be observed in the position as in Askeptosaurus; it is perhaps obscured due to crushing.

It is difficult to reconstruct the original po- 


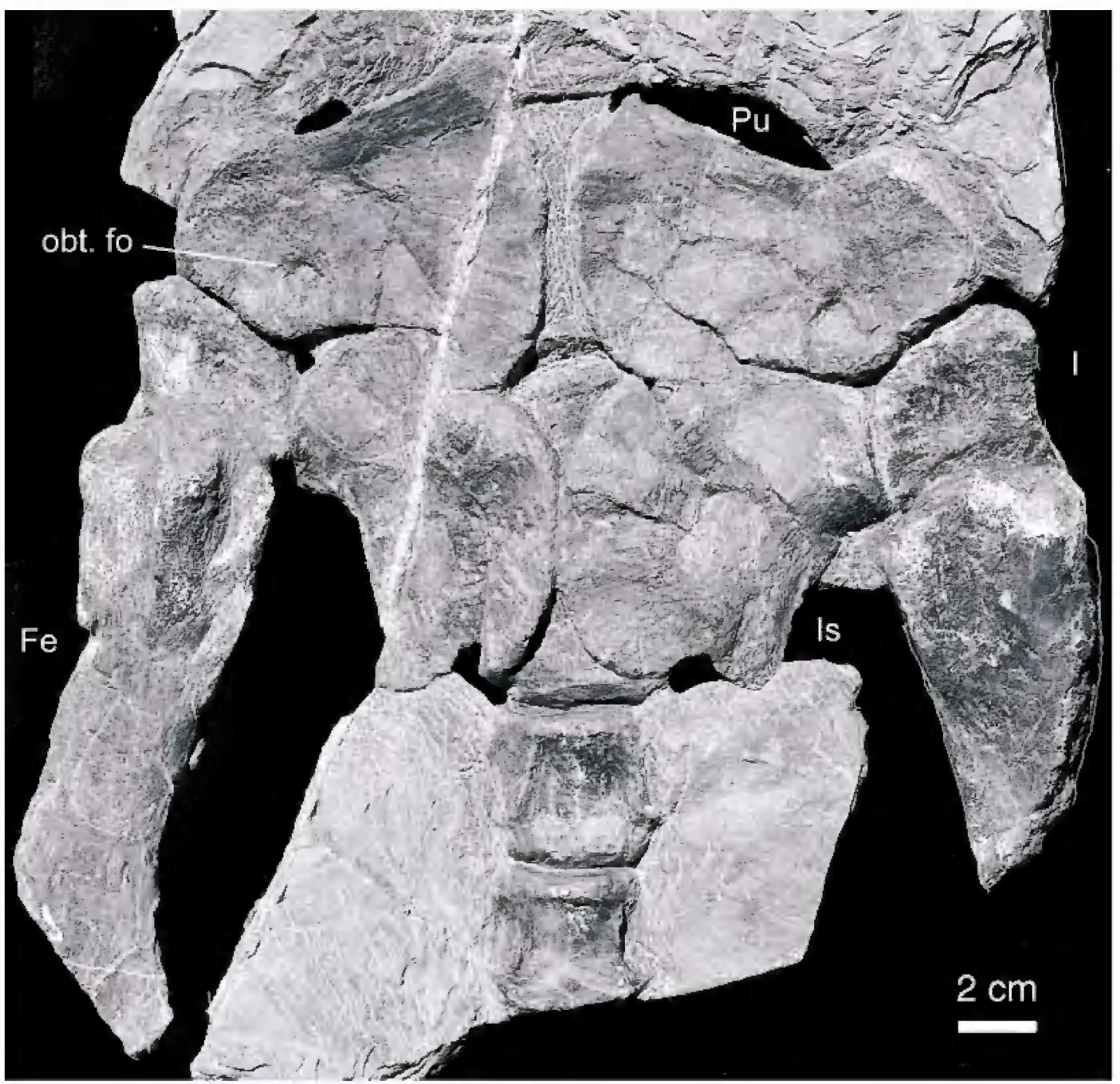

Fig. 10. Anshunsaurus huangguoshuensis, pelvic girdle in situ in ventral view (specimen IVPP 11835-4). See appendix 1 for anatomical abbreviations.

sition of coracoids in IVPP V11834. If the right coracoid is thought to be preserved in articulation with the right scapula, then the side with a straight margin is ventral and contacts the interclavicle; nevertheless the shape of the coracoids is quite different from that of the holotype. If we accepted that shape should be at least similar in two specimens, then the axial/anteroposterior direction of two coracoids should be reversed. This is less possible than the previous hypothesis.

\section{Pelvic Girdle}

The pelvis consists of three elements, ilium, ischium, and pubis. It is completely preserved in articulation in the holotype. In the holotype (figs. 6, 10), only the ilia can be seen in dorsal view; the ischiums and pubes are covered by the vertebrae and ribs dorsally, but they are completely exposed ventrally. A vein of calcite splits the sacral rib and also goes across the right pubis and right ischium. The bones are displaced along this vein. The pelvic girdle is exposed in ventral view in 
IVPP V11834. The following description is mainly based on the holotype. No thyroid fenestra presents in Anshunsaurus, it shows a weak notch in the ventral margin of the pubo-ischiadic plate where the two bones meet. This is similar to Hescheleria (Rieppel, 1987), corroborating the conclusion that the thyroid fenestra is absent in Askeptosaurus (Müller, 2002).

\section{ILIUM}

The ilium is similar to that of Askeptosaurus in shape and mainly exposed in medial view (fig. 6). It forms the dorsal part of the acetabulum and contacts the sacral ribs at its medial side. The ilium does not fuse with the ribs. The dorsal part of the ilium consists of an elongated process that is directed strongly posterodorsally. Posterodorsally, the process becomes increasingly flattened but slightly narrowing into the distal direction, with a sharp dorsal and ventral edge. The dorsal edge of the ilium is rugose, which may have served for muscle attachment, that is, iliofemoralis and iliofibularis muscles. There is no development of a preacetabular process. The posterodorsal wing of the ilium spans about two vertebral centra. The basal part of the ilium, sutured to the ischium and pubis and contributing to the formation of the acetabulum, is distinctly expanded and presents a convex ventral margin.

\section{PUBIS}

The pubis is the most expanded element of the pelvic girdle. It is a broad plate of bone with an enlarged ventral portion. The posterodorsal part of the pubis contributes to the formation of the acetabulum. The small, oval obturator foramen is positioned anteroventrally to the contact with the ilium. The ventral margin of the bone is convex, and the dorsal margin is nearly triangular. Its posterior margin, shorter than the anterior one, meets the ilium along its complete extension. The anterior margin of the pubis is strongly concave, whereas the outline of the posterior edge is only slightly concave. The right pubis seems to be wider than the left one in ventral view; this is caused by the offset along the calcite vein.

\section{ISCHIUM}

The ischium is a more or less semicircular plate of bone. Its narrow anterodorsal portion forms the posteroventral portion of the acetabulum. Its anterodorsal margin is slightly concave, the posterodorsal margin is strongly concave, and the ventral margin is convex. The outline of the anterior and posterior margins is not so obvious, but it seems that the anterior one is slightly convex, corresponding to the posterior margin of the pubis, whereas the posterior margin is concave as in IVPP V11834. The ischium is thickened on the anterodorsal area; the bone becomes increasingly flattened into the ventral direction.

\section{LIMBS}

Anshunsaurus bears well-developed foreand hindlimbs, although both are relatively short in relation to the length of the trunk. The forelimb is shorter than the hindlimb. In contrast to the terrestrial reptiles generally, several details of the extremities such as muscle scars, processes and epiphyses are not present or at least very difficult to detect.

\section{FORELIMB}

Preservation allows both the flexor (dorsal) and the extensor (ventral) side of the forelimb to be described. The forelimb is nearly complete in IVPP V11834 (fig. 9), whereas most of the hand is lost in the holotype (fig. 5).

\section{HUMERUS}

The humerus (fig. 11) is the most robust and longest element of the forelimb skeleton. There is a notable torsion in the bone so that both heads are twisted to one another. The proximal and distal articular surfaces are strongly rounded. The proximal head pinches to a narrow shaft and the shaft rapidly expands to the distal side, forming a broad, convex end. A prominent crest, the deltopectoral crest, originates near the head and mainly lies in the middle of the ventral surface. The crest is most distinct on its central part, fading away in the distal and proximal direction, but the crest is more slender proximally than distally. There is no significant 


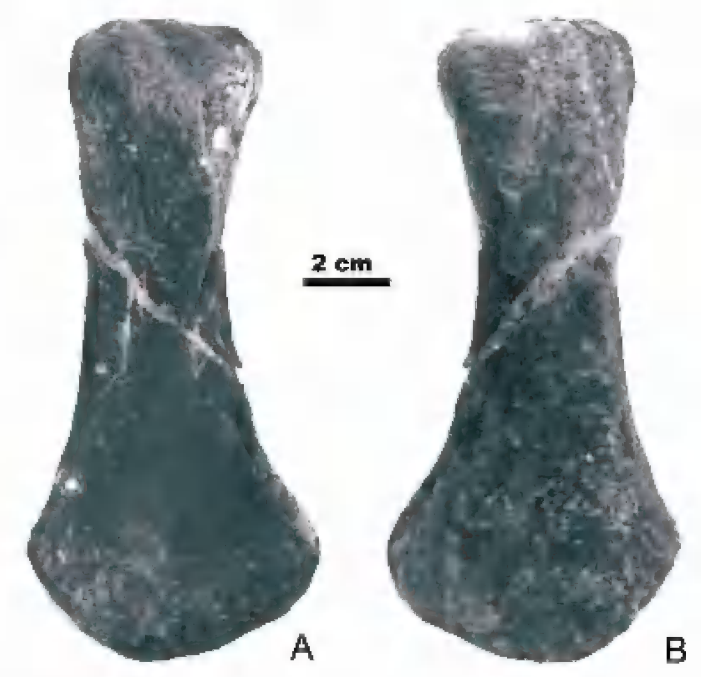

Fig. 11. Anshunsaurus huangguoshuensis, right humerus of holotype in (A) ventral and (B) dorsal view.

development of a supinator process, ectepicondyle, or entepicondyle, nor is there any trace of a respective foramen. Radial and ulnar condyles are not well developed either.

\section{RADIUS}

The radius is a relatively stout bone. It is stouter and broader than the ulna. The radius is characterized by a slight proximal expansion and marked distal expansion. The proximal margin is almost straight whereas the distal one is convex. The medial margin is more concave than the lateral one.

\section{ULNA}

The ulna is slightly shorter than the radius and lacks an ossified olecranon. The widest part of the distal portion is nearly the same as that of the proximal one. The proximal head varies in shape in the two specimens: The margin is round and slightly convex in the holotype but is nearly straight or even slightly concave in IVPP V11834. A different degree of ossification may be the cause. The distal articular surface shows a convex margin. The ulna is significantly constricted in the shaft area, and shows concave lateral and medial margins. The ulna encloses a pronounced interosseal space with the radius.

\section{ManUs}

Seven rounded ossified elements are present in the left carpus of the holotype whereas only four and half elements are preserved in the right carpus; six and five, respectively, are present in IVPP V11834. Two proximal elements are present, ulnare and intermedium. A small element, the centrale, is situated between the intermedium and the distal carpals 2 and 3 in the holotype. Four distal carpals, distal carpals 1 to 4 , which are adjacent to the metacarpals, form a distally arched carpus. The intermedium is the largest element of the carpus, and of rectangular shape with rounded edges. The ulnare, contacting the intermedium and distal carpal 4, is generally smaller than distal carpal 4 , but it is slightly larger than the latter in the right hand of IVPP V11834. The centrale is approximately half as large as the intermedium in Askeptosaurus, but it is much smaller than the intermedium and is the smallest bone in the carpus here. Distal carpal 4 is the largest of all distal carpals. Distal carpal 3 is similar to the centrale in size in the holotype, but it is notably bigger than distal carpals 1 and 2 in IVPP V11834. These kinds of variation also are observed in Askeptosaurus.

Five metacarpals are shown in Anshunsaurus as is general in tetrapods. Metacarpal 1 is the shortest bone, being prominently widened both on its two ends and in the shaft area. The proximal articular surface is the most expanded part. The remaining metacarpals are relatively slender. All are nearly equal in size; only metacarpal 2 is slightly shorter.

The phalanges are not so well preserved, but a least formula of 2-3-4-4-4 can be counted. Compared to the general formula of $2-3-4-5-3$, it is notable that the fifth digit possesses one additional element. The phalanges are generally smaller than the metacarpals. The proximal phalanges of the first and the fifth digits are slightly longer than that of the second and the third, and the first two are slender whereas the last two are stout. The state of the phalanges in the fourth is unclear. The phalanges tend to become somewhat smaller distally. The ungual phalanges are triangular in shape with a sharp distal tip. 


\section{HiNDLIMB}

The hindlimb is completely preserved in IVPP V11834 (fig. 12), whereas only parts of the femur and the fibula are present in the holotype (figs. 6, 10). The left hindlimb of IVPP V11834 is exposed in dorsal (anterior) view, whereas the right limb is observed in medial view.

\section{FEMUR}

The incomplete femora in the holotype are mainly observed in ventral view whereas their dorsal sides are partly covered by the ilium. The right femur in IVPP V11834 is broken and exposed in medial view; the left femur is mainly exposed in dorsal view with the head partially covered by the pelvic girdle.

The femur is an elongated bone of cylindrical shape that is longer than the humerus. The femoral heads are not so well preserved, but it is clear that they are rounded, weakly convex, and at least about the same width as the distal end. A well-developed internal trochanter is shifted somewhat posteriorly (laterally) on the ventral aspect of the bone. This crest can also be observed in IVPP V11834, developed as a modest expansion at the medial edge of the proximal articular surface. This suggests that the two heads were affected by a slight torsion. There is little evidence of a fourth trochanter, and the adductor crest is absent. The intertrochanteric fossa is reduced. The anterior edge of the femur is smoothly concave; the posterior edge is straight to form a pronounced angulation. The femoral distal end shows two facets: a medial major one, which is slightly concave, for receiving the convex head of the tibia and a lateral small one, which is angled with the major one, for articulating to the fibula.

\section{TIBIA}

The tibia is a cylindrical bone like the femur. The proximal end, clearly expanding, is wider than the little-expanded distal end. The proximal end is slightly convex, but the distal end is flat. The shaft does not significantly constrict, and shows slight curvatures both in mediolateral and dorsoventral views.

\section{FIBULA}

The fibula is roughly as long as the tibia, but shows a distinctly different shape. The proximal head shows torsion related to other parts, and is only slightly broader than the shaft. The bone becomes more flattened toward the distal end, and bears a greatly expanded distal head. The latter is fan shaped and nearly three times as broad as the shaft, with the medial edge being slightly sharper than the external one. The margin of the distal articular surface is convex.

\section{Pes}

The tarsus presents six bones, two proximal and four distal elements. The proximal bones are interpreted as astragalus and calcaneum; the distal elements represent distal tarsals $1-4$. The astragalus is the most prominent element, being approximately the size of the calcaneum plus the fourth distal tarsal. It is broad and roughly kidney shaped, its proximolateral facet articulating with the fibula, and the proximomedial edge contacting the tibia. Laterally, the astragalus meets the calcaneum; distally, it articulates with all four tarsals with a convex margin. The calcaneum is a rounded bone, with the proximal side articulating with the fibula, the lateral side with the astragalus, and the distal side with the fourth distal tarsal. A notch for the perforating artery cannot be observed. The distal tarsals vary in size. Distal tarsals 1-3 are more or less equally large, although the first distal tarsal is sometimes slightly more expanded. Distal tarsal 4 is the largest element. The distal tarsals all contact their neighboring elements and meet their respective metatarsal, although the fourth also perhaps articulate with metatarsal 5 .

The five metatarsals are longer and relatively more slender than the complementary elements in the manus. The first metatarsal is shorter and stouter than the remaining elements and shows a distinct proximal expansion. The fifth metatarsal is only slightly longer than the first one, expanded at least at its proximal end. It is partially concealed by the haemal arch. Metatarsals 2-4 are similar in size and shape. They are slender, elongated elements with slightly expanded heads; the 


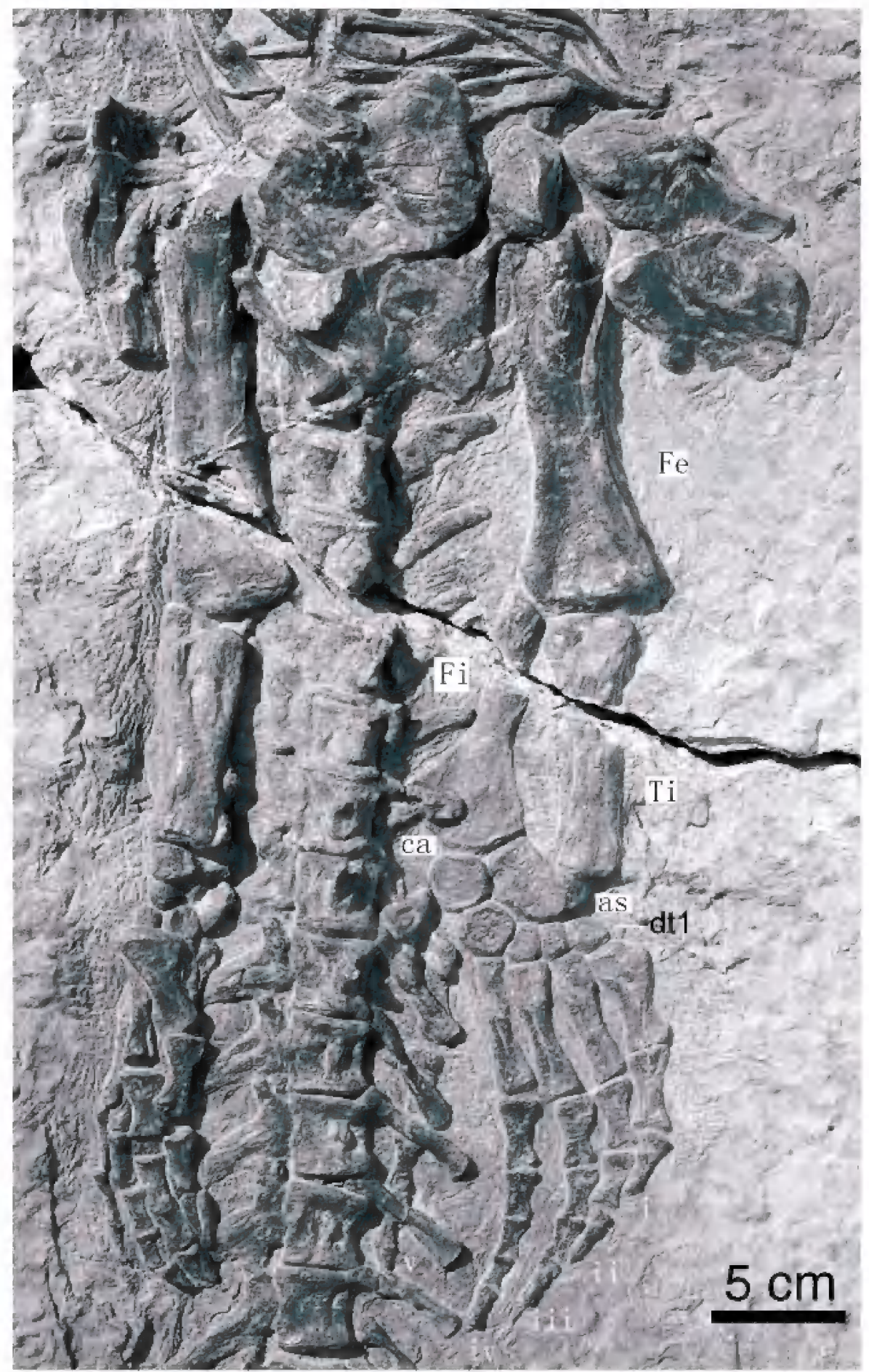

Fig. 12. Anshunsaurus huangguoshuensis, hindlimb of specimen IVPP 11834, left side in dorsal view, right side in medial view. See appendix 1 for anatomical abbreviations. 
proximal heads are slightly wider than the distal ones.

The phalangeal formula of the pes is 2-3$4-5-4$, as is the general pattern of reptiles. The proximal phalange of the first digit is the longest, the remaining proximal phalanges are shorter and stouter, and that of the fifth digit is the shortest. All phalanges decrease in size toward the distal direction. The ungual phalanges are of the same shape as in the manus.

\section{MEASUREMENTS AND RATIOS}

The size and proportions were analyzed in Askeptosaurus to document individual variation (Müller, 2002). Because only two specimens are available for this study, this aim is not suitable here. Here we present the measurements and ratios for further study.

The skull length was measured from the anterior tip of the snout to the level of the posterior tip of the supratemporal, whereas the mandible length represents the distance from the symphysis to the caudal tip of the articular. The standard length is the length of four articulated vertebrae in the posterior part of the trunk. Following Rieppel (1989), the four posteriormost dorsals should be used for standard length. However, as in the specimens studied by Müller (2002), the four posteriormost dorsals are not so well preserved, so the measurement was based on well-preserved posterior dorsal vertebrae. As the lengths of the dorsals are subequal, this would not be a problem. The glenoid-acetabulum length represents the distance from the posteromedial corner of the proximal humerus head to the posteromedial corner of the proximal femur head. If possible, measurements were taken for both sides of the respective animal. A complete list of measurements and ratios is presented in appendix 2 .

\section{PHYLOGENETIC POSITION OF ANSHUNSAURUS}

Anshunsaurus is clearly distinct from the thalattosaur genus, Xinpusaurus, which occurs in the same locality and horizon. They are easily differentiated by the number of cervical vertebrae, the direction of the clavicle, and the shape of scapula; even the long snout of Xinpusaurus bamaolinensis tapers to a pointed tip.

In all thalattosaurs, Anshunsaurus is similar to Endennasaurus and Askeptosaurus in the presence of a long-necked body and a long-snouted skull. Anshunsaurus especially looks like Askeptosaurus, although they are differentiated by some detailed characters. It was interpreted as the sister taxon of Askeptosaurus based on 16 skull characters by Rieppel et al. (2000). This hypothesis of a monophyletic long-necked Askeptosauridae is not supported by some later analyses (Liu and Rieppel, 2001; Jiang et al., 2004), although it remains the result of Muiller (2005). In Müller's cladogram, Endennasaurus clusters with Anshunsaurus and Askeptosaurus.

To evaluate the phylogenetic relationships within thalattosaurs, and to test the monophyly of Askeptosauridae in particular, a new analysis was conducted, including all valid thalattosaur genera and species (Agkistrognathus campebelli, Anshunsaurus huangguoshuensis, Askeptosaurus italicus, Clarazia schinzi, Endennasaurus acutirostris, Hescheleria ruebeli, Nectosaurus halius, Paralonectes merriami, Thalattosaurus alexandrae, Thalattosaurus borealis, Xinpusaurus bamaolinensis, Xinpusaurus suni). Araeoscelidia and Younginiformes were selected as outgroups in the phylogenetic analysis of Müller (2005), but they are specified as $P e$ trolacosaurus kansensis and Youngina capensis in this study; Prolacerta broomi is also added as an outgroup. Thus composite taxa are avoided in this phylogenetic analysis, following the suggestion by others (Bininda-Emonds et al., 1998; Norell et al., 2001). In sum, 12 ingroups and 3 outgroups are applied in this analysis.

The following characters were selected for this test; most of them are adapted from previous analyses. The characters are coded on the basis of personal observation and literature sources (tables 1, 2).

\section{Character List}

The abbreviations that appear within square brackets in the list below refer to the published reference and the number of times in which the character or a similar character has been applied in numerical phylogenetic 
TABLE 1

Taxon-Character Data Matrix

\begin{tabular}{lllllllllllllllll}
\hline \hline \multicolumn{1}{c}{ Character number: } & 1 & 2 & 3 & 4 & 5 & 6 & 7 & 8 & 9 & 10 & 11 & 12 & 13 & 14 & 15 \\
\hline Petrolacosaurus kansensis & 0 & 0 & 0 & 0 & 0 & 0 & 0 & 0 & 0 & 0 & 0 & 0 & 0 & 0 & 0 \\
Youngina capensis & 0 & 0 & 0 & 0 & 0 & 0 & 0 & 0 & 0 & 0 & 0 & 0 & 0 & 1 & 1 \\
Prolacerta broomi & 0 & 0 & 0 & 0 & 0 & 0 & 0 & 0 & 0 & 0 & 0 & 0 & 0 & 0 & 1 \\
Agkistrognathus campebelli & $?$ & $?$ & $?$ & $?$ & $?$ & $?$ & $?$ & $?$ & $?$ & $?$ & $?$ & $?$ & $?$ & $?$ & $?$ \\
Anshunsaurus huangguoshuensis & 2 & 2 & 0 & 0 & 1 & 1 & 1 & 0 & 1 & 0 & 0 & 0 & 0 & 1 & 0 \\
Askeptosaurus italicus & 2 & 2 & 0 & 0 & 1 & 1 & 0 & 0 & 1 & 0 & 0 & 0 & 0 & 2 & 0 \\
Clarazia schinzi & 1 & 1 & 1 & 0 & 0 & $?$ & 1 & 0 & 0 & 1 & $?$ & $?$ & 1 & 0 & 0 \\
Endennasaurus acutirostris & 2 & 1 & 0 & $?$ & 1 & 0 & $?$ & $?$ & $?$ & $?$ & $?$ & 0 & $?$ & 1 & 1 \\
Hescheleria ruebeli & 1 & 1 & 2 & 0 & 0 & 0 & 1 & 0 & $?$ & $?$ & $?$ & 0 & $?$ & $?$ & $?$ \\
Nectosaurus halius & 1 & 1 & 2 & $?$ & 0 & $?$ & 1 & 0 & $?$ & $?$ & $?$ & 1 & $?$ & 0 & 1 \\
Paralonectes merriami & 1 & 1 & 2 & $?$ & $?$ & $?$ & $?$ & 0 & $?$ & $?$ & $?$ & $?$ & $?$ & $?$ & $?$ \\
Thalattosaurus alexandrae & 2 & 1 & 1 & 1 & 0 & 0 & $?$ & 0 & 0 & $?$ & 1 & 1 & 1 & 0 & 1 \\
Thalattosaurus borealis & 2 & 1 & 1 & 0 & 0 & $?$ & $?$ & 0 & $?$ & 2 & $?$ & $?$ & $?$ & $?$ & $?$ \\
Xinpusaurus bamaolinensis & 2 & 1 & 0 & 1 & 0 & 1 & 1 & 1 & 0 & 1 & 1 & 1 & 0 & 0 & 1 \\
Xinpusaurus suni & 1 & 1 & 1 & 1 & 0 & 0 & 1 & 1 & 0 & 1 & 1 & 1 & 0 & 0 & 1 \\
\hline
\end{tabular}

studies. Reference abbreviations are: $\mathbf{N}=$ Nicholls 1999; $\mathbf{R}=$ Rieppel et al. 2000; L $=$ Liu and Rieppel 2001; J = Jiang et al. 2004; $\mathbf{M}=$ Müller et al., 2005.

\section{SKULL}

1. Rostrum absent (0); rostrum present but preorbital region of skull not distinctly longer than postorbital region of skull (1) (distance from tip of snout to anterior margin of orbit shorter than distance from anterior margin of orbit to posterior tip of supratemporal); rostrum present but preorbital region of skull distinctly longer than postorbital region of skull (2) (distance from tip of snout to anterior margin of orbit longer than distance from anterior margin of orbit to posterior tip of supratemporal). [R1, L1, J1, M1]

2. Rostrum absent $(0)$; rostrum tapering to pointed tip, that is, with convergent lateral margins in front of external nares (1); rostrum tapering to blunt tip, that is, with parallel lateral margins in front of external nares (2). [R1, L1, J1, M1]

3. Tip of snout (rostrum) straight (0), tip of snout (rostrum) slightly deflected ventrally (1), or strongly deflected ventrally (2). [N19, R2, L2, M2, J2] Definition revised.

According to Rieppel et al. (MS), a vertically descending premaxillary rostrum is a unique morphology shared by Hescheleria and Nectosaurus, perhaps also Paralonectes; so they are coded as " 2 ".
4. Anterior narial margin formed by premaxilla (0) or largely or exclusively by the nasal (1). [J19]

A possible septomaxilla was suggested before the external naris in Endennasaurus (Müller et al., 2005), but this part is broken, so coded as "?" here. The nasal projects anteriorly of the external naris in new specimen of Xinpusaurus suni (Rieppel and Liu, MS), and it looks like this also is the case in V11860, so it is coded as " 1 ".

5. Premaxilla has a distinct posteroventral process extending far beyond the anterior narial margin in ventral side $(0)$ or no such a structure (1) [J21]. Character definition and polarity has been changed.

Coding Clarazia as (0) following Müller (2002).

6. Maxilla is longer (0) or shorter (1) than part of premaxilla forming upper jaw maxilla.

7. Maxilla does not (0) or does (1) form part of the outer orbital rim.

8. Anterior part of alveolar margin of maxilla straight $(0)$ or distinctly curved upward (1). [L18, J17]

9. Nasals do not (0) or do (1) extend backward to level behind anterior margin of orbit. [R6, L6, J5, M11]

In the skull reconstruction of Youngina (fig. 6 in Gow 1975), it seems that the nasals extend backward to a level behind the ante- 
TABLE 1

(Extended)

\begin{tabular}{ccccccccccccccccc}
\hline \hline 16 & 17 & 18 & 19 & 20 & 21 & 22 & 23 & 24 & 25 & 26 & 27 & 28 & 29 & 30 & 31 & 32 \\
\hline 0 & 0 & 0 & 0 & 0 & 0 & 0 & 0 & 0 & 0 & 0 & 0 & 0 & 0 & 0 & 0 & 0 \\
0 & 0 & 0 & 0 & 0 & $?$ & 0 & 0 & 0 & 0 & 0 & 0 & 0 & 0 & 0 & 0 & 0 \\
0 & 0 & 0 & 1 & 0 & 1 & 0 & 0 & 0 & 0 & 0 & 0 & 0 & 0 & 0 & 0 & 0 \\
$?$ & $?$ & $?$ & $?$ & 1 & $?$ & $?$ & $?$ & 0 & 0 & $?$ & $?$ & $?$ & $?$ & $?$ & $?$ & $?$ \\
1 & 0 & 1 & 0 & 0 & 0 & 0 & 0 & 0 & 0 & 1 & 1 & 0 & 0 & 1 & 0 & 0 \\
0 & 0 & 0 & 0 & 0 & 1 & 0 & 0 & 0 & 0 & 1 & 1 & 0 & 0 & 1 & 1 & 0 \\
1 & 1 & $?$ & 1 & 1 & 0 & 0 & 1 & 1 & 1 & 0 & 0 & 0 & 1 & 1 & 1 & 1 \\
1 & $?$ & $?$ & $?$ & 0 & $?$ & 1 & $?$ & $?$ & $?$ & 1 & 1 & 0 & 0 & 1 & 0 & 0 \\
1 & $?$ & $?$ & $?$ & 1 & $?$ & 0 & 1 & $?$ & 1 & $?$ & 0 & 1 & 1 & 1 & 1 & 1 \\
1 & $?$ & $?$ & $?$ & $?$ & 1 & 0 & 1 & $?$ & 0 & 0 & $?$ & 1 & $?$ & 0 & 0 & 2 \\
$?$ & $?$ & $?$ & $?$ & 1 & $?$ & 0 & 1 & 1 & 1 & 0 & $?$ & $?$ & $?$ & $?$ & $?$ & $?$ \\
1 & 1 & 1 & $?$ & 1 & 1 & 1 & 1 & 1 & 1 & 0 & $?$ & 1 & 1 & 0 & 0 & 2 \\
$?$ & $?$ & $?$ & $?$ & $?$ & $?$ & 1 & $?$ & $?$ & 1 & 0 & $?$ & $?$ & $?$ & $?$ & $?$ & $?$ \\
1 & 0 & 0 & $?$ & 1 & 1 & 0 & 0 & 0 & 1 & 0 & 0 & 1 & $?$ & 0 & 1 & 2 \\
1 & $?$ & 0 & 1 & 1 & 1 & 0 & 0 & 0 & 1 & 0 & 0 & 1 & 1 & 0 & 1 & 2 \\
\hline
\end{tabular}

rior margin of the orbit, but this is not true based on original figures.

10. Anterolateral processes of frontal remain broadly separated from external naris (0) or anterolateral processes of frontal closely approach (1) or even enter the posterior margin of external naris (2). [R7, L7, M12, J6]

It is clear that only the anteromedial process nearly reaches the external naris in Askeptosaurus, not the anterolateral process. This character was miscoded for derived state by Müller et al. (2005).

11. Nasal in contact with prefrontal $(0)$, nasal separated from prefrontal (1). [N14, $\mathrm{R} 8, \mathrm{~L} 8, \mathrm{~J} 7, \mathrm{M} 13]$

The lacrimal is viewed as absent in Askeptosaurus, so prefrontal in Askeptosaurus is the same as that in Anshunsaurus, so this character is coded as " 0 ".

12. Prefrontal without (0) or with (1) shieldlike extension along the anterodorsal orbital margin. [J20]

13. Frontal separate from supratemporal (0), in contact with supratemporal (1). [R11, L11, J10, M15] Character definition had been revised.

For the holotype of Xinpusaurus bamaolinensis (SPCV30015), it is clear showing that frontal separate from supratemporal in the description and figure 1a (Cheng, 2003), but the reverse state is present in the reconstruction. This part is poorly preserved in
"X. kohi" (GMPKU2000/005). So the coding for both species of Xinpusaurus is " 0 ".

14. Posterolateral processes of frontal do not extend beyond anterior margin of lower temporal fossa (0), extend far beyond anterior margin of lower temporal fossa (1), are absent (2). [R10, L10, J9, M14]

The posterolateral processes are moderately developed in Petrolacosaurus and Prolacerta, well developed in Youngina. So the polarity is changed.

15. Frontoparietal suture interdigitating, oriented transversely for most of its part (0) or deeply embayed in the shape of a broad $\mathrm{V}$, the apex pointing forward (1). [L17, J16, M16]

16. Postfrontal and postorbital separate (0) or fused (1). [N16, R12, L12, J11, M17]

17. Posterior end of squamosal with $(0)$ or without ventral process (1). [R14, L14, J14, M19]

18. Quadrate without (0) or with (1) distinct medial lamina. [M20]

19. Pineal foramen large and located in front of midpoint of parietal skull table (0) or small and located at center or somewhat behind parietal skull table (1). [R16, L16, $\mathrm{J} 15, \mathrm{M} 22]$ The polarity is changed.

\section{LOWER JAW}

20. Dorsal margin of dentary symphysis straight (0), recurved (1). [N22] 
TABLE 2

Specimens and Literature Consulted for Construction of Phylogenetic Data Matrix in Table 1

\begin{tabular}{ll}
\hline \hline \multicolumn{1}{c}{ Taxon } & \multicolumn{1}{c}{ Information sources } \\
\hline $\begin{array}{l}\text { Petrolacosaurus kansensis } \\
\text { Youngina capensis }\end{array}$ & (Reisz, 1981) \\
Prolacerta broomi & (Gow, 1975) \\
Agkistrognathus campebelli & (Gow, 1975; Modesto and Sues, 2004) \\
Anshunsaurus huangguoshuensis & (Nicholls and Brinkman, 1993) \\
Askeptosaurus italicus & IVPP V11834, IVPP V11835 \\
Clarazia schinzi & (Kuhn-Schnyder, 1952, 1960, 1971; Müller, 2002; Nopsca, 1925) \\
Endennasaurus acutirostris & PIMUZ A/III 211 (Müller, 2002; Peyer, 1936a; Rieppel, 1987) \\
Hescheleria ruebeli & (Müller et al., 2005) \\
Nectosaurus halius & PIMUZ T2469 (Peyer, 1936b; Rieppel, 1987; Rieppel et al., MS) \\
Paralonectes merriami & UCMP 9124 (Nicholls, 1999; Rieppel et al., MS) \\
Thalattosaurus alexandrae & (Nicholls and Brinkman, 1993) \\
Thalattosaurus borealis & UCMP 9085 (Nicholls, 1999) \\
Xinpusaurus bamaolinensis & (Nicholls, 1999) \\
Xinpusaurus suni & SPCV 30015, GMPKU 2000/005 (Cheng, 2003; Jiang et al., 2004) \\
\hline
\end{tabular}

21. Surangular and angular equally well exposed on the lateral side of lower jaw (0) or surangular exposure much more extensive (1). [J24] Coding for Askeptosaurus as "1".

\section{TEETH}

22. Premaxilla dentition is present $(0)$ or absent (1) (state 1 includes also pseudodont projections). [N29, M3]

23. Diastema between premaxillary and maxillary teeth absent $(0)$, present (1). [N28, R3, L3, J3, M4]

24. Anteriormost dentary teeth upright (0), procumbent as their implantation curves around anterior end of dentary (1). [R4, L4, M5]

25. Posterior teeth on dentary conical and pointed (0), bulbous and blunt (1). [part of R5, L5, J4, M6]

The character definition is revised, so the coding has changed for Xinpusaurus (1).

26. Palatal dentition (on vomer and pterygoid) present (0) or absent (1). [N25, 26, 27 M7, 8, 9]

\section{POSTCRANIAL}

27. Number of cervical vertebrae is less than $10(0)$ or higher than $10(1)$. [N35, M24]

28. Neural spines of posterior cervicals and dorsals are relatively low (0) or at least two times higher than broad (1). [M28, J27]

29. Proximal caudal neural spines are rel- atively low (0) or distinctly elongated and at least three times higher than broad (1). [M29]

Because the postcranium of Xinpusaurus "kohi" appears to be a composite and it is not known in the holotype of $X$. bamaolinensis, coding is "?" in this species.

30. Scapula is slender and elongate $(0)$ or broad and rounded (1).

31. Deltopectoral crest is well developed (0) or reduced (1). [N38, M26]

32 . Radius is slender (0), slightly expanded (1), or strongly expanded and roughly kidney shaped (2). [J28]

33. Femur proximal and distal ends about equal in width (0) or distal end markedly widened (1). [J29]

34. Fibula distal end narrow, that is, width less than half of length (0), expanded (1).

Some characters included in former studies are deleted from this analysis because they are uninformative for the analysis of ingroup relationships. These characters include:

1. Nasals meet each other medially $(0)$ or are separated due to the posterior extent of the premaxilla (1). [M10]

2. Anteromedial processes of frontals that enter in between nasal and premaxilla are shorter (0) or longer (1) than anterolateral processes of frontal. [R9, L9, J8]

3 . The quadratojugal is present $(0)$ or absent (1). [M21] 


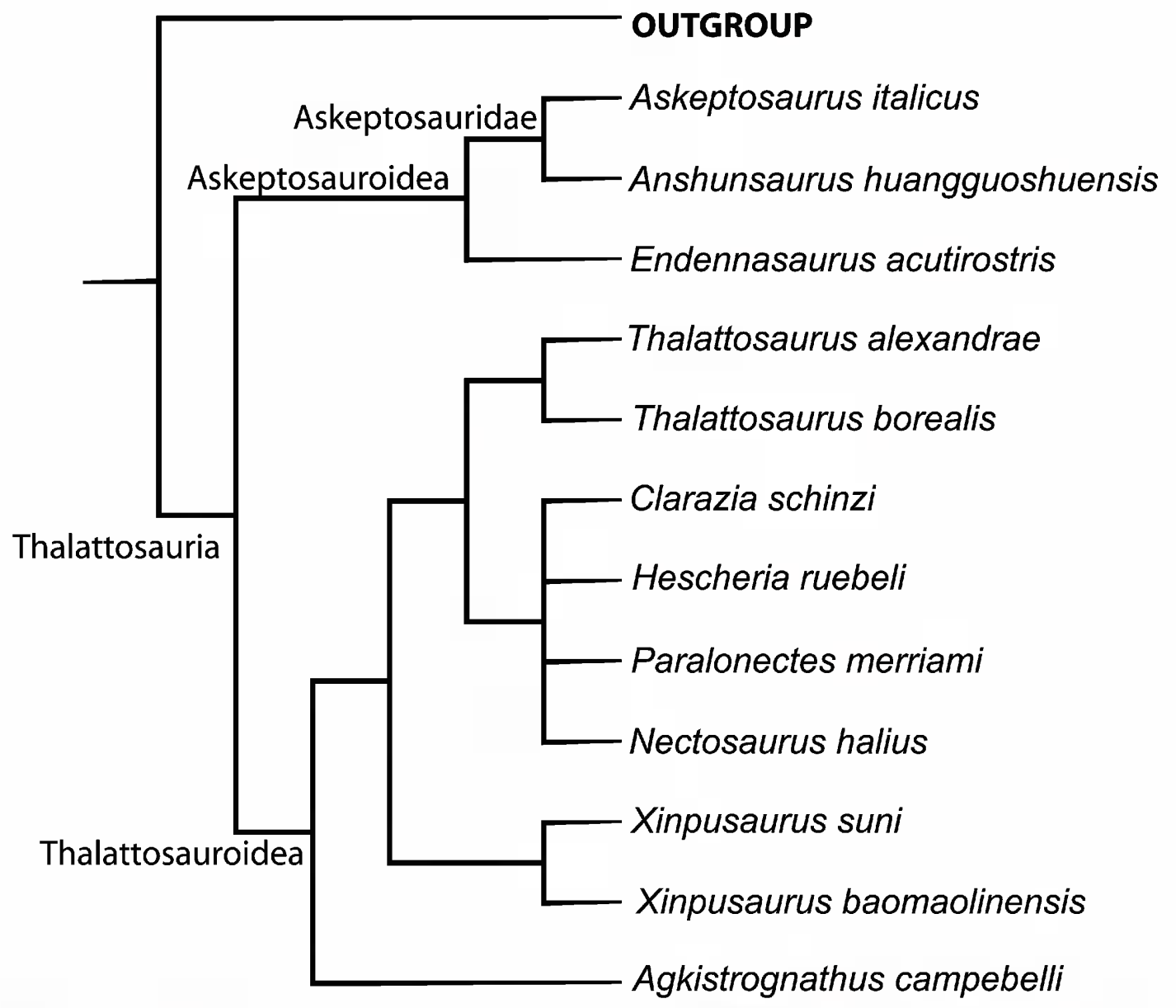

Fig. 13. Phylogenetic relationships of Anshunsaurus within Thalattosauria based on the analysis of 34 characters ( $\mathrm{RI}=0.77$.

4. Lacrimal present (0) or absent (1). [N12, J18]

5. Upper temporal fenestra present and large $(0)$, reduced and slitlike (1), or absent (2). [N1, R13, L13, J12, M18]

All multistate characters were treated unordered and unweighted. Implementing branch-and-bound search option of the PAUP* 4.0b10 (Swofford, 2001), the 15 most parsimonious trees resulted, with a length of 62 (consistency index 0.65 , retention index 0.77). In the strict consensus tree (fig. 13), the monophyly of Askeptosauridae (see Rieppel et al., 2000) and Thalattosauroidea (Nopsca, 1928; see also Rieppel 1987) are recovered, Endennasaurus is the sister taxon of Askeptosauridae, Thalattosaurus and Xinpusaurus are monophyletic genera, Paralonectes and Nectosaurus from North America are closely related to Clarazia and Hescheleria from Monte San Giorgio.

Askeptosaurus and Anshunsaurus are unequivocally diagnosed by the rostrum tapering to a blunt tip (Char. 2[2], CI = 1), the maxilla is shorter than the part of the premaxilla forming the upper jaw maxilla (Char. $6[1], \mathrm{CI}=0.50$ ), and the frontoparietal suture interdigitating, oriented transversely for most of its part (Char. 15[0], CI $=0.33$ ). Based on DELTRAN character optimization, the shared characters also include the nasal extends backward to a level behind the anterior margin of the orbit (Char. 9[1], CI = $1)$. 
The family Askeptosauridae (KuhnSchnyder, 1952) included only one genus and species for a long time. Anshunsaurus was included as the second member of this group (Rieppel et al., 2000), although the monophyly of this family is in doubt. Endennasaurus was proposed as being closely related to thalattosaurs, especially Askeptosaurus, by the nominator (Renesto, 1992). This opinion was accepted by Nicholls (1999), but not accepted and excluded in our previous analysis (Rieppel et al., 2000). Subsequent research by Müller et al. (2005) supported its position as a thalattosaur. In this study, it also turns out to be closely related to Askeptosaurus and Anshunsaurus. So it is reasonable to include Endennasaurus in Askeptosauroidea (Kuhn-Schnyder, 1971). The unequivocal synapomorphies include: premaxilla has no distinct posteroventral process extending beyond the anterior narial margin in ventral side (Char. 5[1], CI = 1); posterolateral processes of frontal extending far beyond anterior margin of lower temporal fossa (Char. $14[1]$, CI $=0.67$ ); palatal dentition (on vomer and pterygoid) absent (Char. 26[1], CI $=1$ ); the number of cervical vertebrae more than 10 (Char. 27[1], CI = 1); and the scapula broad and rounded (Char. 30[1], CI = $0.5)$.

The monophyly of Thalattosauroidea is supported by all analyses including this one (Nicholls, 1999; Rieppel et al., 2000; Liu and Rieppel, 2001; Müller, 2002; Jiang et al., 2004). An unequivocally shared derived character of this group is dorsal margin of dentary symphysis recurved (Char. 20[1], CI $=1$ ). Based on ACCTRAN character optimization, the shared characters also include tip of snout (rostrum) slightly deflected ventrally (Char. 3[1], CI $=0.5$ ), anterolateral processes of frontal closely approach external naris (Char. 10[1], CI = 1), nasal separated from prefrontal (Char. 11[1], CI = 1), prefrontal with shieldlike extension along the anterodorsal orbital margin (Char. 12[1], CI $=0.5$ ), pineal foramen small and located at center or somewhat behind parietal skull table (Char. 19[1], CI $=0.5$ ), neural spines of posterior cervicals and dorsals at least two times higher than broad (Char. 28[1], CI = 0.5 ), proximal caudal neural spines distinctly elongated and at least three times higher than broad (Char. 29[1], CI = 1), the radius strongly expanded and roughly kidney shaped (Char. 32[2], CI = 1), the femur distal end markedly widened (Char. 33[1], CI = 1), the slender fibula (Char. 34[1], CI $=0.5$ ).

The intrarelationships of Thalattoauroidea are different from all previous results, although the exact relationships of the four genera are still unclear. Although Claraziidae (Peyer, 1936b) may be monophyletic, Thalattosauridae (Merriam 1904) is definitely not. A sister relationship of Xinpusaurus with Nectosaurus is not supported by this study.

\section{ACKNOWLEDGMENTS}

We are grateful to $\mathrm{Li}$ Jinling and $\mathrm{Li}$ Chun for generous access to the thalattosaur material kept at the Institute of Vertebrate $\mathrm{Pa}$ leontology and Paleoanthropology, Chinese Academy of Sciences. Ding Jinzhao and Zhang Hong prepared the specimens; Zhang Jie and Zhang Fucheng helped to photograph. Donald Brinkman and Johannes Müller kindly reviewed an earlier draft of this paper. This work is partly supported by National Science Foundation of China (No. 40302007).

\section{REFERENCES}

Benton, M.J. 1985. Classification and phylogeny of the diapsid reptiles. Zoological Journal of the Linnean Society 84: 97-164.

Bininda-Emonds, O.R.P., H.N. Bryant, and A.P. Russell. 1998. Supraspecific taxa as terminals in cladistic analysis: implicit assumptions of monophyly and a comparison of methods. Biological Journal of the Linnean Society 64: 101-133.

Cheng, L. 2003. A new species of Triassic Thalattosauria from Guanling, Guizhou. Geological Bulletin of China 22: 274-277.

Dalla Vecchia, F.M. 1993. Reptile remains from the Middle-Upper Triassic of the Carnic and Julian Alps (Friuli-Venezia Giulia, northeastern Italy). Gortania-Atti del Museo Friulano di Storia Naturale 15: 49-66.

Evans, S.E. 1988. The early history and relationships of the Diapsida. In M.J. Benton (editor), The phylogeny and classification of the tetrapods: 221-260. Systematics Association Special Publication. Oxford: Clarendon Press.

Gow, C.E. 1975. The morphology and relationships of Youngina capensis Broom and Prolacerta broomi Parrington. Palaeontologia Africana 18: 89-131. 
Jiang, D.-Y., M.W. Maisch, Y.-L. Sun, A.T. Matzke, and W.-C. Hao. 2004. A new species of Xinpusaurus (Thalattosauria) from the upper Triassic of China. Journal of Vertebrate Paleontology 24: 80-88.

Kuhn-Schnyder, E. 1952. Die Triasfauna der Tessiner Kalkalpen. XVII. Askeptosaurus italicus Nopcsa. Schweizerische Palaeontologische Abhandlungen 69: 1-52.

Kuhn-Schnyder, E. 1960. Über einen Schultergürtel von Askeptosaurus italicus Nopsca aus der anisischen Stufe der Trias des Monte San Giorgio (Kt. Tessin, Schweiz). Ecologae Geologicae Helvetiae 53: 805-810.

Kuhn-Schnyder, E. 1971. Über einen Schädel von Askeptosaurus italicus Nopcsa aus der Mittleren Trias des Monte San Giorgio (Kt. Tessin, Schweiz). Abhandlungen des Hessischen Landesamtes für Bodenforschung 60: 89-98.

Liu, J. 1999. New discovery of sauropterygian from Triassic of Guizhou, China. Chinese Science Bulletin 44: 1312-1315.

Liu, J. 2001. The postcranial skeleton of Xinpusaurus. In T. Deng and Y. Wang (editors), Proceedings of the Eighth Annual Meeting of the Chinese Society of Vertebrate Paleontology: 18. Beijing: Ocean Press.

Liu, J., and O. Rieppel. 2001. The second thalattosaur from the Triassic of Guizhou, China. Vertebrate PalAsiatica 39: 77-87.

Merriam, J.C. 1904. A new marine reptile from the Triassic of California. University of California Publications in Geological Sciences 3: 419-421.

Merriam, J.C. 1905. The Thalattosauria: a group of marine reptiles from the Triassic of California. California Academy of Sciences Memoirs 5: $1-38$.

Merriam, J.C. 1908. Notes on the osteology of the thalattosaurian genus Nectosaurus. University of California Publications in Geological Sciences 5: 217-223.

Modesto, S.P., and H.-D. Sues. 2004. The skull of the Early Triassic archosauromorph reptile Prolacerta broomi and its phylogenetic significance. Zoological Journal of Linnean Society 140: 335-351.

Motani, R. 1999. Phylogeny of the Ichthyopterygia. Journal of Vertebrate Paleontology 19: 473-496.

Müller, J. 2002. A revision of Askeptosaurus italicus and other thalattosaurs from the European Triassic, the interrelationships of thalattosaurs, and their phylogenetic position within diapsid reptiles (Amniota, Eureptilia). Ph.D. thesis, Johannes Gutenberg-Universitat, Mainz.

Müller, J. 2003. Early loss and multiple return of the lower temporal arcade in diapsid reptiles. Naturwissenschaften 90: 473-476.

Müller, J. 2004. The relationships among diapsid reptiles and the influence of taxon selection. In G. Arratia, R. Cloutier, and V.H. Wilson (editors), Recent advances in the origin and early radiation of vertebrates: 379-408. Munich: Dr. Friedrich Pfeil.

Müller, J. in press. The anatomy of Askeptosaurus italicus from the Middle Triassic of Monte San Giorgio, and the interrelationships of thalattosaurs (Reptilia, Diapsida). Canadian Journal of Earth Sciences.

Müller, J., S. Renesto, and S.E. Evans. 2005. The marine diapsid reptile Endennasaurus (Reptilia: Thalattosauriformes) from the Late Triassic of Italy. Palaeontology 48: 1-16.

Nicholls, E.L. 1999. A reexamination of Thalattosaurus and Nectosaurus and the relationships of the Thalattosauria (Reptilia: Diapsida). PaleoBios 19: 1-29.

Nicholls, E.L., and D.B. Brinkman. 1993. New thalattosaurs (Reptilia: Diapsida) from the Triassic sulphur formation of Wapiti Lake, British Columbia. Journal of Paleontology 67: 263278.

Nopsca, F.V. 1925. Askeptosaurus, ein neues Reptil aus der Trias von Besano. Cbl. Min. Geol. Pal. B: 265-267.

Nopsca, F.V. 1928. The genera of reptiles. Palaeobiologica 1: 163-188.

Norell, M.A., J.M. Clark, and P.J. Makovicky. 2001. Phylogenetic relationships among coelurosaurian theropods. In J. Gauthier and L.F. Gall (editors), New perspectives on the origin and early evolution of birds: proceedings of the International Symposium in honor of John $\mathrm{H}$. Ostrom: 49-67. New Haven, CT: Peabody Museum of Natural History, Yale University.

Peyer, B. 1936a. Die Triasfauna der Tessiner Kalkalpen. X. Clarazia schinzi nov. gen. nov. sp. Abhandlungen der schweizerischen paläontologischen Gesellschaft 57: 1-61.

Peyer, B. 1936b. Die Triasfauna der Tessiner Kalkalpen. XI. Hescheleria rübeli nov. gen. nov. sp. Abhandlungen der Schweizerischen Paläontologischen Gesellschaft 58: 1-48.

Reisz, R.R. 1981. A diapsid reptile from the Pennsylvanian of Kansas. University of Kansas Special Publication of the Museum of Natural History 7: $1-74$.

Renesto, S. 1992. The anatomy and relationships of Endennasaurus acutirostris (Reptilia, Neodiapsida), from the Norian (Late Triassic of Lombardy). Rivista Italiana di Paleontologia e Stratigrafia 97: 409-430.

Rieppel, O. 1987. Clarazia and Hescheleria, a reinvestigation of two problematical reptiles from 
the Middle Triassic of Monte San Giorgio, Switzerland. Palaeontographica A 195: 101129.

Rieppel, O. 1989. A new pachypleurosaur (Reptilia: Sauropterygia) from the Middle Triassic of Monte San Giorgio, Switzerland. Philosophical Transactions of the Royal Society of London Series B 323: 1-73.

Rieppel, O. 1998. The systematic status of Hanosaurus hupehensis (Reptilia, Sauropterygia) from the Triassic of China. Journal of Vertebrate Paleontology 18: 545-557.

Rieppel, O., and H. Hagdorn. 1998. Fossil reptiles from the Spanish Muschelkalk (Montral and Alcover, Province Tarragona). Historical Biology 13: 77-97.

Rieppel, O., and J. Liu. Submitted. On Xinpusaurus (Reptilia: Thalattosauria). Journal of Vertebrate Paleontology.

Rieppel, O., J. Liu, and H. Bucher. 2000. The first record of a thalattosaur reptile from the Late Triassic of southern China (Guizhou Province,
PR China). Journal of Vertebrate Paleontology 20: 507-514.

Rieppel, O., J. Müller, and J. Liu. Submitted. Rostral structure in Thalattosauria (Reptilia, Diapsida). Canadian Journal of Earth Sciences.

Romer, A.S. 1956. Osteology of the reptiles. Chicago: University of Chicago Press, $772 \mathrm{pp}$.

Sander, P.M., O. Rieppel, and H. Bucher. 1994. New marine vertebrate fauna from the Middle Triassic of Nevada. Journal of Paleontology 68: 676-680.

Storrs, G.W. 1991. Note on a second occurrence of Thalottosaur Remains (Reptilia, Neodiapsida) in British-Columbia. Canadian Journal of Earth Sciences 28: 2065-2068.

Swofford, D.L. 2001. PAUP*. Phylogenetic Analysis Using Parsimony (* and Other Methods). version 4.0b10. Sunderland, MA: Sinauer Associates.

Yin, G., X. Zhou, Z. Cao, Y. Yu, and Y. Luo. 2000. A prelimary study on the early late Triassic marine reptiles from Guanling, Guizhou, China. Geology Geochemistry 28: 1-23.

\section{APPENDIX 1}

\section{Anatomical AbBreViations}

$\begin{array}{ll}\text { A } & \text { angular } \\ \text { Art } & \text { articular } \\ \text { as } & \text { astragalus } \\ \text { Bo } & \text { basioccipital } \\ \text { ca } & \text { calcaneum } \\ \text { Cl } & \text { clavicle } \\ \text { Co } & \text { coracoid } \\ \text { cr } & \text { caudal rib } \\ \text { cul pr } & \text { cultriform process } \\ \text { D } & \text { dentary } \\ \text { dc } & \text { distal carpal } \\ \text { dt } & \text { distal tarsal } \\ \mathrm{F} & \text { frontal } \\ \text { Fe } & \text { femur } \\ \mathrm{Fi} & \text { fibula } \\ \mathrm{Hu} & \text { humerus } \\ \mathrm{Hy} & \text { hyoid } \\ \mathrm{I} & \text { ilium } \\ \text { Icl } & \text { interclavicle } \\ \text { in } & \text { intermedium } \\ \text { Is } & \text { ischium } \\ \mathrm{J} & \text { jugal } \\ \mathrm{M} & \text { maxilla }\end{array}$

$\begin{array}{ll}\text { N } & \text { nasal } \\ \text { obt. fo } & \begin{array}{l}\text { obturator foramen } \\ \text { opisthotic }\end{array} \\ \text { Op } & \text { parietal } \\ \text { P } & \text { palatine } \\ \text { Pl } & \text { premaxilla } \\ \text { Pm } & \text { postorbitofrontal } \\ \text { Pof } & \text { prearticular } \\ \text { Pra } & \text { prefrontal } \\ \text { Prf } & \text { prootic } \\ \text { Pro } & \text { parabasisphenoid } \\ \text { Ps-Bs } & \text { pterygoid } \\ \text { Pt } & \text { pubis } \\ \text { Pu } & \text { quadrate } \\ \text { Q } & \text { radius } \\ \text { R } & \text { surangular } \\ \text { Sa } & \text { scapula } \\ \text { Sc } & \text { supraocipital } \\ \text { So } & \text { splenial } \\ \text { Sp } & \text { squamosal } \\ \text { Sq } & \text { sacral rib } \\ \text { sr } & \text { supratemporal } \\ \text { St } & \text { tibia } \\ \text { Ti } & \text { ulna } \\ \text { U } & \text { ulnare } \\ \text { ul } & \text { vomer } \\ \text { V } & \end{array}$


APPENDIX 2

Anshunsaurus huangguoshuensis Measurements $(L=$ left; $R=$ right $)$

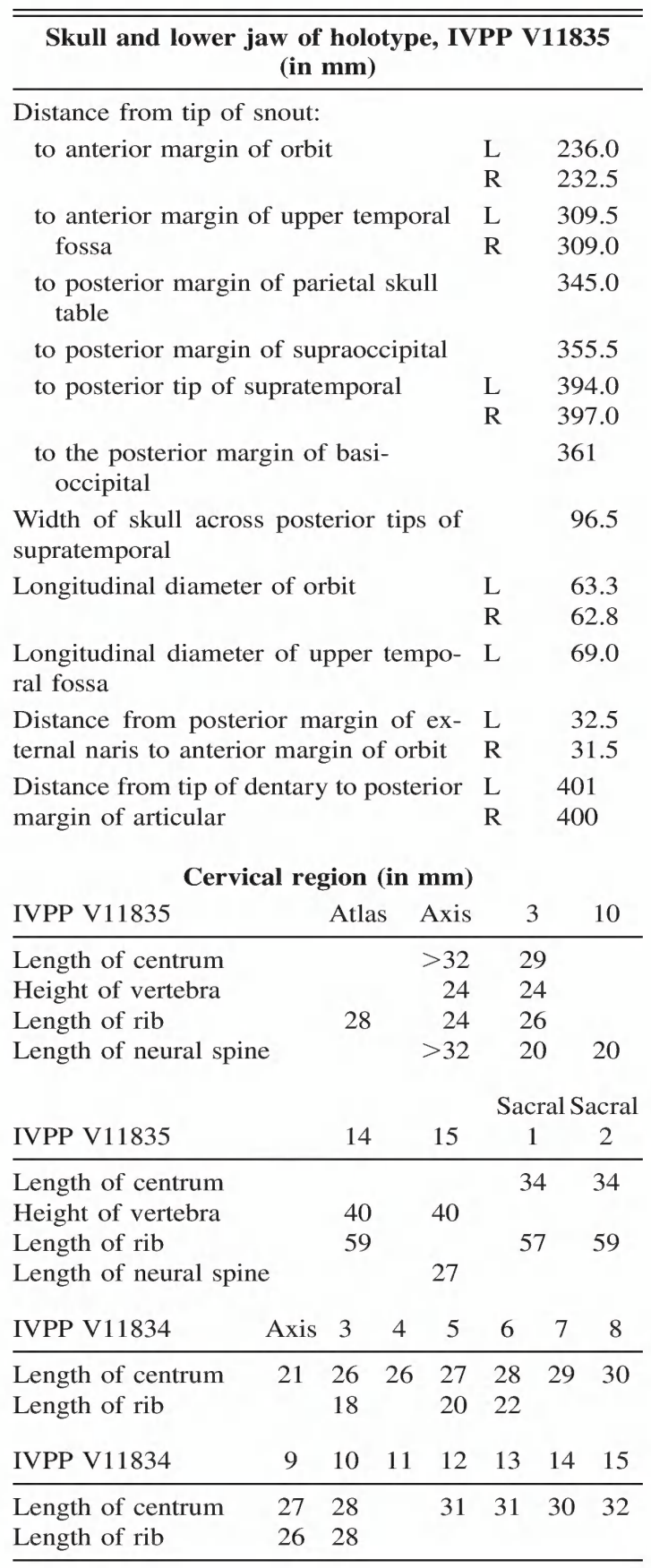

APPENDIX 2

(Continued)

\begin{tabular}{lcc}
\hline \hline \multicolumn{3}{c}{ Left sacral ribs } \\
& $\begin{array}{c}\text { First } \\
\text { rib }\end{array}$ & $\begin{array}{c}\text { Second } \\
\text { rib }\end{array}$ \\
\hline Length & $57 \mathrm{~mm}$ & $59 \mathrm{~mm}$ \\
Width of distal end & $32 \mathrm{~mm}$ & $35 \mathrm{~mm}$ \\
Width of proximal end & $12 \mathrm{~mm}$ & $23 \mathrm{~mm}$
\end{tabular}

Limb girdle

\begin{tabular}{lrr} 
& V11835 & V11834 \\
\hline $\begin{array}{l}\text { Length of interclavicle } \\
\text { Width of interclavicle }\end{array}$ & $22 \mathrm{~cm}$ & $21 \mathrm{~cm}$ \\
Length of clavicle & $>17 \mathrm{~cm}$ & $17 \mathrm{~cm}$ \\
Length of coracoid (axial) & $119 \mathrm{~mm}$ \\
Width (or height) of coracoid & $>73 \mathrm{~mm}$ \\
Length of ilium & $122 \mathrm{~mm}$ \\
Width of basal ilium & $55 \mathrm{~mm}$ \\
Length of L pubis (axial) & $72 \mathrm{~mm}$ \\
Height of L pubis & $82 \mathrm{~mm}$ \\
Length of ischium & $73 \mathrm{~mm}$ \\
Height of ischium & $77 \mathrm{~mm}$
\end{tabular}

Stylo- and zuegopodium (in mm)

\begin{tabular}{|c|c|c|c|c|c|}
\hline \multirow[b]{2}{*}{ IVPP V11835 } & \multicolumn{3}{|c|}{ Humerus } & \multicolumn{2}{|c|}{ Radius } \\
\hline & & $\mathrm{L}$ & $\mathrm{R}$ & $\mathrm{L}$ & $\mathrm{R}$ \\
\hline Length & & 152 & 152 & 91 & 91 \\
\hline Width of proximal end & & 46 & 44 & 36 & 36 \\
\hline Minimal width & & 35 & 35 & 22 & 23 \\
\hline \multirow[t]{2}{*}{ Width of distal end } & & 73 & 72 & 45 & 44 \\
\hline & \multicolumn{3}{|c|}{ Ulna } & \multirow[b]{2}{*}{ Femur } & \multirow[b]{2}{*}{ Fibula } \\
\hline IVPP V11835 & & $\mathrm{L}$ & $\mathrm{R}$ & & \\
\hline Length & & 89 & 88 & $>156$ & \\
\hline Width of proximal end & & 37 & 35 & 54 & \\
\hline Minimal width & & 20 & 22 & & \\
\hline \multirow[t]{2}{*}{ Width of distal end } & & 37 & & & 58 \\
\hline & \multicolumn{3}{|c|}{ Humerus } & \multicolumn{2}{|c|}{ Radius } \\
\hline IVPP V11834 & & $\mathbf{L}$ & $\mathrm{R}$ & $\mathrm{L}$ & $\mathrm{R}$ \\
\hline Length & & 141 & 134 & 85 & 85 \\
\hline Width of proximal end & & & 41 & $30 ?$ & 30 \\
\hline Minimal width & & 30 & 30 & 20 & 21 \\
\hline \multirow[t]{2}{*}{ Width of distal end } & & 67 & 66 & 37 & 37.5 \\
\hline & \multicolumn{2}{|c|}{ Ulna } & Femur & Tibia & Fibula \\
\hline IVPP V11834 & $\mathrm{L}$ & $\mathbf{R}$ & $\mathrm{L}$ & $\mathrm{L}$ & $\mathrm{L}$ \\
\hline Length & 82 & 79 & $160 ?$ & 100 & 101 \\
\hline Width of proximal end & 34 & 36 & $35 ?$ & 37 & 20 \\
\hline Minimal width & 18 & 18 & 28 & 18 & 17 \\
\hline Width of distal end & & 32 & 53 & 24 & 51 \\
\hline
\end{tabular}


APPENDIX 2

(Continued)

\begin{tabular}{|c|c|c|c|c|c|}
\hline \multicolumn{6}{|c|}{$\begin{array}{c}\text { Measurements taken on specimen } \\
\text { IVPP V11834 }\end{array}$} \\
\hline \multicolumn{6}{|c|}{$\begin{array}{l}\text { Length of lower jaw } 37.5 \mathrm{~cm} \\
\text { Length of cervical vertebrae } 44 \mathrm{~cm} \\
\text { Length of caudal vertebrae }>170 \mathrm{~cm} \\
\text { Presacral length (including skull) } 175 \mathrm{~cm} \\
\text { Length from glenoid cavity to acetabulum } 73 \mathrm{~cm}\end{array}$} \\
\hline \multirow[b]{2}{*}{ Metacarpal } & \multicolumn{2}{|l|}{ I } & II & \multicolumn{2}{|c|}{ III } \\
\hline & $\mathrm{L}$ & $\mathrm{R}$ & $\mathrm{R}$ & $\mathrm{L}$ & $\mathrm{R}$ \\
\hline Length & 40 & 39 & 44 & 49 & 47 \\
\hline Width of proximal end & 29 & 27 & 16 & 15 & 17 \\
\hline Minimal width & 13 & 12 & 11 & 9 & 10 \\
\hline \multirow[t]{2}{*}{ Width of distal end } & & 19 & 17 & 15 & 16 \\
\hline & \multicolumn{3}{|c|}{ IV } & \multicolumn{2}{|l|}{ V } \\
\hline Metacarpal & \multicolumn{2}{|l|}{ 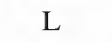 } & & $\mathrm{R}$ \\
\hline Length & 47 & 47 & \multirow{2}{*}{\multicolumn{2}{|c|}{18}} & 47 \\
\hline Width of proximal end & 11 & 19 & & & 15 \\
\hline Minimal width & 10 & 11 & & 8 & 11 \\
\hline Width of distal end & 13 & 16 & & & 16 \\
\hline $\begin{array}{l}\text { Left } \\
\text { metatarsal }\end{array}$ & I & II & III & IV & V \\
\hline Length & 45 & 53 & 55 & 54 & 42 \\
\hline Width of proximal end & 25 & $21 ?$ & $19 ?$ & 18 & \\
\hline Minimal width & 12 & 11 & 11 & 11 & \\
\hline Width of distal end & 19 & 14 & 17 & 15 & 15 \\
\hline
\end{tabular}

APPENDIX 2

(Continued)

\begin{tabular}{|c|c|c|c|c|}
\hline \multicolumn{5}{|c|}{ Some ratios in two specimens of Anshunsaurus } \\
\hline Measurements & & IVPP & \multicolumn{2}{|c|}{$\begin{array}{l}\text { IVPP } \\
\text { V11834 }\end{array}$} \\
\hline acetabulum length & & & 0.52 & \\
\hline Head length to humerus & & & & \\
\hline length & 2.60 & & 2.70 & 2.84 \\
\hline $\begin{array}{l}\text { Humerus length to glenoid- } \\
\text { acetabulum length }\end{array}$ & & & 0.19 & 0.18 \\
\hline $\begin{array}{l}\text { Humerus length to standard } \\
\text { length }\end{array}$ & 0.98 & & & \\
\hline $\begin{array}{l}\text { Humerus length to femur } \\
\text { length }\end{array}$ & & & 0.88 & \\
\hline $\begin{array}{l}\text { Humerus length to length of } \\
\text { metacarpal } 3\end{array}$ & & & 2.88 & 2.85 \\
\hline $\begin{array}{l}\text { Humerus length to radius } \\
\text { length }\end{array}$ & 1.67 & 1.67 & 1.66 & 1.58 \\
\hline $\begin{array}{l}\text { Humerus length to distal } \\
\text { width }\end{array}$ & 2.08 & 2.11 & 2.10 & 2.03 \\
\hline $\begin{array}{l}\text { Radius length to standard } \\
\text { length }\end{array}$ & 0.59 & & & \\
\hline $\begin{array}{l}\text { Humerus minimal width to } \\
\text { humerus distal width }\end{array}$ & 0.23 & 0.23 & 0.21 & 0.22 \\
\hline $\begin{array}{l}\text { Femur length to glenoid- } \\
\text { acetabulum length }\end{array}$ & & & 0.22 & \\
\hline $\begin{array}{l}\text { Femur length to fibula } \\
\text { length }\end{array}$ & & & 1.58 & \\
\hline
\end{tabular}


Complete lists of all issues of the Novitates and the Bulletin are available at World Wide Web site http://library.amnh.org/pubs. Inquire about ordering printed copies via e-mail from scipubs@amnh.org or via standard mail from: American Museum of Natural History, LibraryScientific Publications, Central Park West at 79th St., New York, NY 10024. TEL: (212) 7695545. FAX: (212) 769-5009.

(2) This paper meets the requirements of ANSI/NISO Z39.48-1992 (Permanence of Paper). 